\title{
Accurate Modeling of Prismatic Type High Current Lithium-Iron-Phosophate (LiFePO4) Battery for Automotive Applications
}

\author{
Farag K. Abo-Elyousr ${ }^{1,2}$, F. N. Abd-Elbar' ${ }^{1}$ H. A. Abo-Zaid ${ }^{1}$, G. H. Rim ${ }^{2}$ \\ ${ }^{1}$ Department of Electrical Engineering, Assiut University, Assiut, Egypt \\ ${ }^{2}$ Department of Energy Conversion, University of Science and Technology, Daejon, Korea \\ Email: farag@au.edu.eg
}

Received September 18, 2012; revised October 22, 2012; accepted November 2, 2012

\begin{abstract}
With accurate battery modeling, circuit designers and automotive control algorithms developers can predict and optimize the battery performance. In this paper, an experimental verification of an accurate model for prismatic high current lithium-iron-phosphate battery is presented. An automotive TSLFP160AHA lithium-iron-phosphate battery bank is tested. The different capacity GBDLFMP60AH battery bank is used to validate the model extracted from the former battery. Effect of current, stacking and SOC upon the battery parameters performance is investigated. Six empirical equations are obtained to extract the prismatic type LiFePO4 model as a function of SOC. Based on comparing the measured and simulated data, a well accuracy of less than $50 \mathrm{mV}$ maximum error voltage with $1.7 \%$ operating time error referred to the measured data is achieved. The model can be easily modified to simulate different batteries and can be extended for wide ranges of different currents.
\end{abstract}

Keywords: State of Charge (SOC); Automotive Battery Dynamics; Battery Modeling Simulators; Lithium-Iron-Phosphate Battery

\section{Introduction}

Regarding automotive and clean energy applications, battery is still widely used as an energy storage device for supplying or delivering electrical energy. There are many types of battery technology such as lead-acid, $\mathrm{NiCd}$, NiMH or Li-ion battery. Lithium-iron-phosphate (LiFePO4) or LFP battery offers good combination of performance, safety, cost, reliability and environmental characteristics. Lithium-iron-phosphate technology utilizes natural phosphate based material. Also, LFP battery has long life cycles up to 2000 times [1-4]. The specific energy for LFP is about $101.5 \mathrm{Wh} / \mathrm{kg}$ [1]. Table 1 shows the different specific energy values versus nominal open circuit voltages for some different batteries [5]. Considering cost, LFP represents $71.6 \%$ of the total cost of Getz retro-fet EV while lithium-ion battery represents $68 \%$ of total cost of i-MiEV [6]. From Table 1 and the above mentioned advantages, LFP battery has superior characteristics than other types. This makes it a futuristic candidate for electric powertrains [7].

Optimizing the battery and predicting its performance is a primary concern for circuit designers and electric vehicle developers. With accurate equivalent circuit modeling done in simulator environment such as power- in-the-loop concept [8], battery sizing and performance with different current waveforms can be predicted to save time and cost of the development procedures. In addition to that, combination of battery with other electrochemical storage systems such as fuel cell or supercapacitor for electric powertrains requires a precise battery modeling [7,9].

Thevenin model is used to model the battery as shown in Figure 1 [10]. In Thevenin model, it is assumed that the parameters are fixed against SOC variation, which is not correct. Linear model considers the effect of the state of charge [11]. However, the battery is modeled by a voltage source and a series resistance only. The impedance based model shown in Figure 2 employs a method called digital frequency response analysis combined with discrete frequency immittance spectroscopy [12]. This model uses complex mathematical procedures to find the ac impedance $\mathrm{Z}$. In addition to that, the model works at fixed SOC and cannot predict battery dc response.

In automotive applications, the battery banks consist of multiple cells. In this paper, an equivalent circuit model based on the experiments done for a TSLFP160AHA LFP cell in a bank is introduced. Mathematical relationships describing the battery parameters variation with SOC are 
Table 1. Energy density versus nominal open circuit voltage.

\begin{tabular}{ccc}
\hline Battery type & $\begin{array}{c}\text { Energy density } \\
(\mathrm{Wh} / \mathrm{kg})\end{array}$ & $\begin{array}{c}\text { Nominal open circuit } \\
\text { voltage }(\mathrm{V})\end{array}$ \\
\hline Lead-acid & $60[7]$ & $2[1]$ \\
NiMH & $40 \sim 60[7]$ & $1.7[1]$ \\
Li-ion & $90[5]$ & $3.5[5]$ \\
LFP & $101.5[1]$ & $3.3[1]$ \\
\hline
\end{tabular}

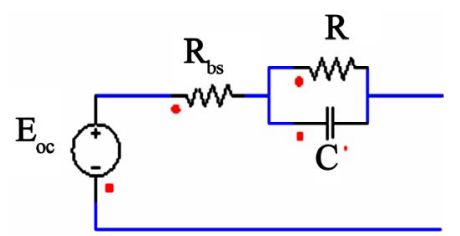

Figure 1. Thevenin battery model.

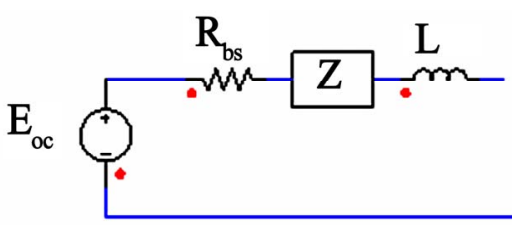

Figure 2. Impedance based battery electrical model.

investigated based on empirical data. The simulation verifications shown in Figure 3 are proposed and implemented in ANSOFT SIMPLORER environment. Although the circuit model is considered as an improvement to Thevenin model, however the parameters recognition equations are new. The model is capable of predicting the electrical characteristics of the battery dynamics regarding automotive applications, in which LFP is used as a non-regen power storage element in powertrains. The model is validated by GBSLFMP60Ah. The operational principle of this model depends on ampere-hour method to calculate SOC and consider parameters variation. Moreover, the effect of stacking and current are discussed in this paper.

This paper is organized as follows. The mathematical derivations of the ampere-hour method are reviewed in Section 2. The test system and measurements carried out on LFP battery are described in Section 3. Mathematical relationships of the battery parameters are extracted in Section 4. Model validation is introduced in Section 5. Finally, the conclusions are given in Section 6.

\section{Ampere-Hour Method}

Considering a step load discharging current, the battery terminal voltage responds in a manner similar to Figure 4. Normally, the battery terminal voltage response includes voltage drop with a sudden and a slow response curve. Therefore, the battery terminal voltage response is described in the short and long term operating conditions by the RC network of Figure 3. The resistance $\left(R_{b s}\right)$ shown in Figure 3 corresponds to the sudden voltage drop illustrated in Figure 4. The first time constant, consisting of $\mathrm{R}_{\text {trans } 1}$ and $\mathrm{C}_{\text {trans } 1}$, represents the short term time constant of the current pulse. The second time constant, consisting of $\mathrm{R}_{\text {trans } 2}$ and $\mathrm{C}_{\text {trans } 2}$, represents the long term response of the current pulse. A voltage equation is investigated to calculate the battery internal voltage as a function of SOC, and then send it to the voltage dependent source $E_{o c}$ to represent the voltage at the battery terminals after considering the drop across the RC network.

Battery terminal voltage transient response can be modeled by any number of time constants. It is a tradeoff between accuracy and complexity. It is referred in [13] based on numerous experimental curves that using two $\mathrm{RC}$ time constants, instead of one or three, is the best tradeoff between accuracy and complexity because two $\mathrm{RC}$ time constants keep errors to within $1 \mathrm{mV}$ for all curve fittings.

To analytically define the physical $\mathrm{R}$ and $\mathrm{C}$ values of the equivalent circuit with constant SOC and temperature, the method discussed in [14] is adopted here. The determination of the short term time constant is explained in

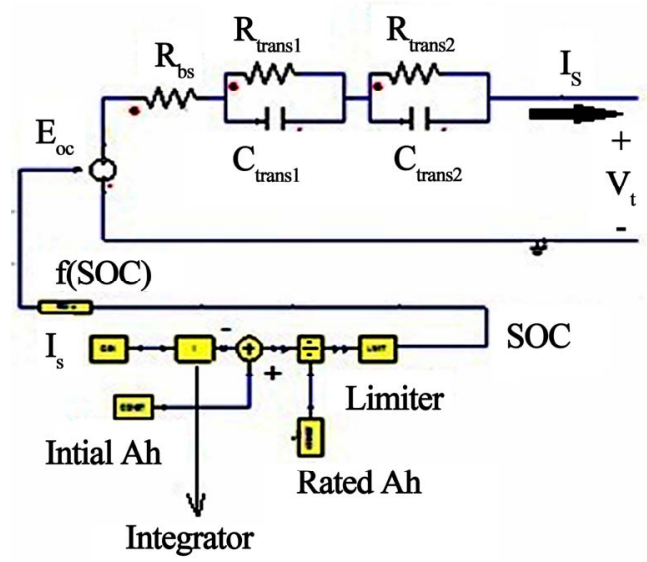

Figure 3. Proposed battery equivalent circuit model.

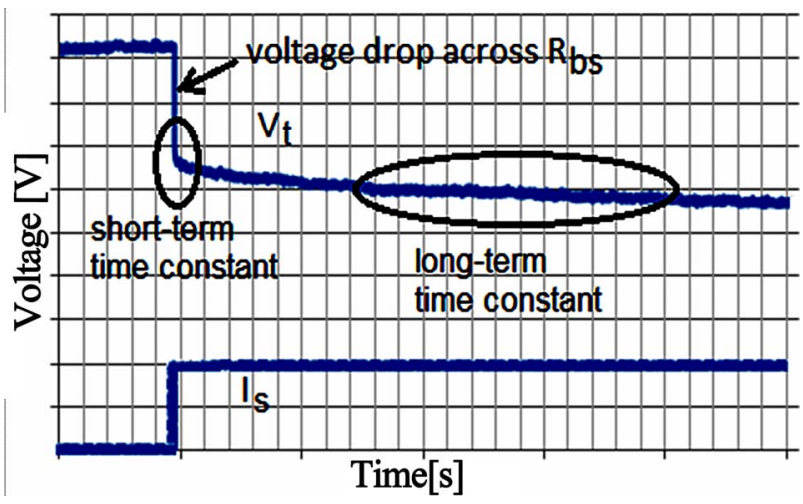

Figure 4. Voltage response for a step load current. 
Appendix A. However, the next equations are added.

In modeling the battery, state of charge (SOC) is an important parameter to be determined. SOC relates the remaining capacity in Ampere-hour (Ah) to the consumed capacity $[3,7,15]$. For deriving the SOC, let $Q_{o}$ be the initial capacity and $Q_{n}$ is the rated capacity. Hence, the available or remaining capacity in Ah designated as $Q_{s}$ and battery SOC are given as in Equations (1) and (2) respectively.

$$
\begin{aligned}
& Q_{s}=Q_{o}-\int i_{s} \mathrm{~d} t . \\
& \mathrm{SOC}=Q_{S} / Q_{n} .
\end{aligned}
$$

where, $i_{s}$ is the battery current. The battery internal voltage $E_{o c}$ and terminal voltage $V_{t}$ are given in Equations (3) and (4) in terms of battery SOC and internal impedance respectively. The symbol (//) in Equation (4) stands for the parallel connection of the electric elements of the corresponding RC network.

$$
\begin{gathered}
E_{o c}=f(\mathrm{SOC}) . \\
V_{t}=E_{o c}-i_{s} \times\left(R_{b s}+R_{\text {trans } 1} / / C_{\text {trans } 1}+R_{\text {trans } 2} / / C_{\text {trans2 }}\right) .
\end{gathered}
$$

\section{Examination with TSLFP160AHA}

To find all the parameters in the proposed model, an experimental battery test system was set up. The battery bank is composed of 30 cells in series. One cell is chosen and its terminal voltage and current are measured as illustrated in Figure 5. The test is done at room temperature. Figure 6 shows the test system workplace. The operating conditions such as temperature, current and cycle number are kept close to each other. The battery open circuit voltage or internal voltage $\left(E_{o c}\right)$ has a strong relationship with battery SOC [15]. The main target is to find this relation so that the battery SOC and hence the remaining capacity in Ah can be estimated with an accurate manner. Therefore, the battery current is chopped during discharging using an IGBT at a very low frequency [12]. At the end of the off-period, the open circuit voltage is measured. The battery voltage waveform is monitored and analyzed to extract the other parameters at fixed SOC and temperature [14]. The measured current and corresponding voltage obtained by Yokogawa oscilloscope for $55 \mathrm{~A}$ is shown in Figure 7. For better accuracy, Tektronix DP07354 oscilloscope is used to measure the chosen cell voltage as depicted in Figure 8.

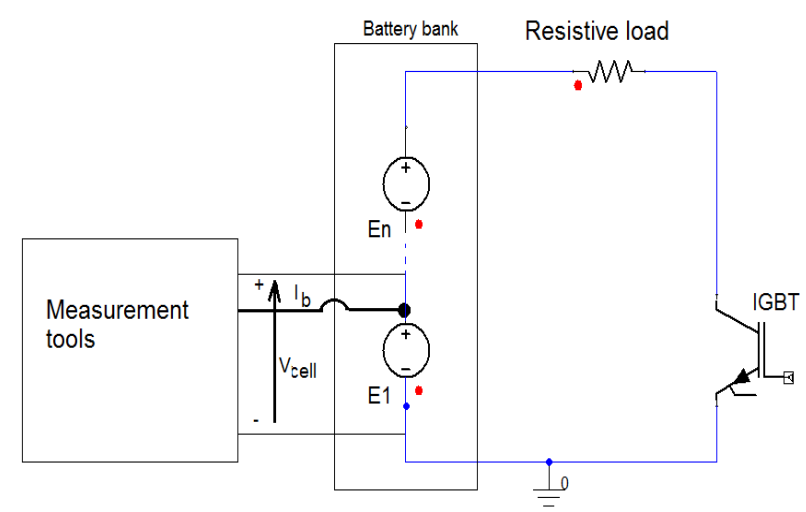

Figure 5. Battery testing connection diagram.

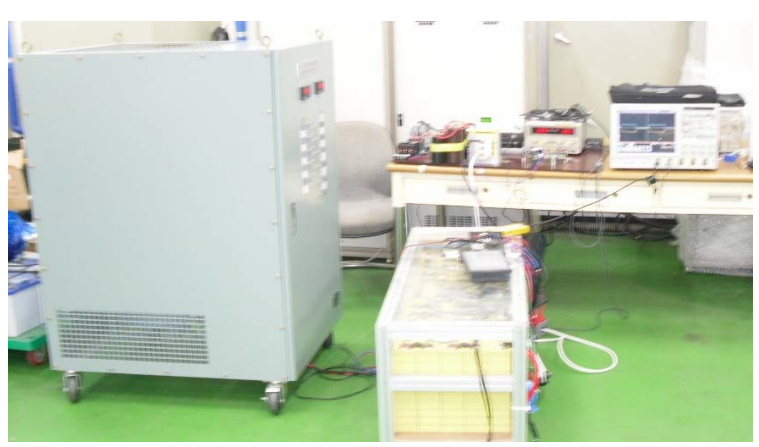

Figure 6. Battery test workplace.

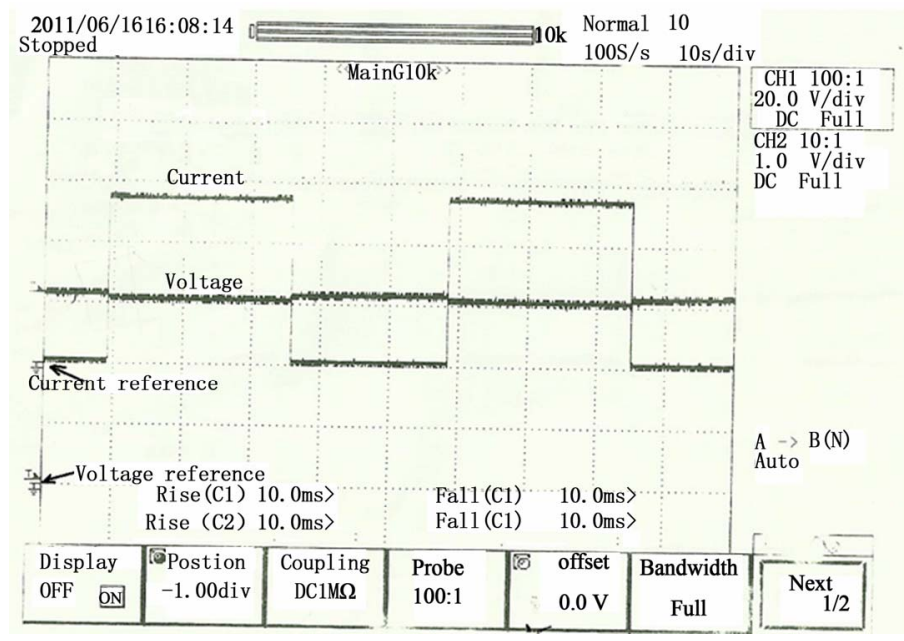

Figure 7. Voltage and current waveforms seen by Yokogawa oscilloscope for $55 \mathrm{~A}$. 


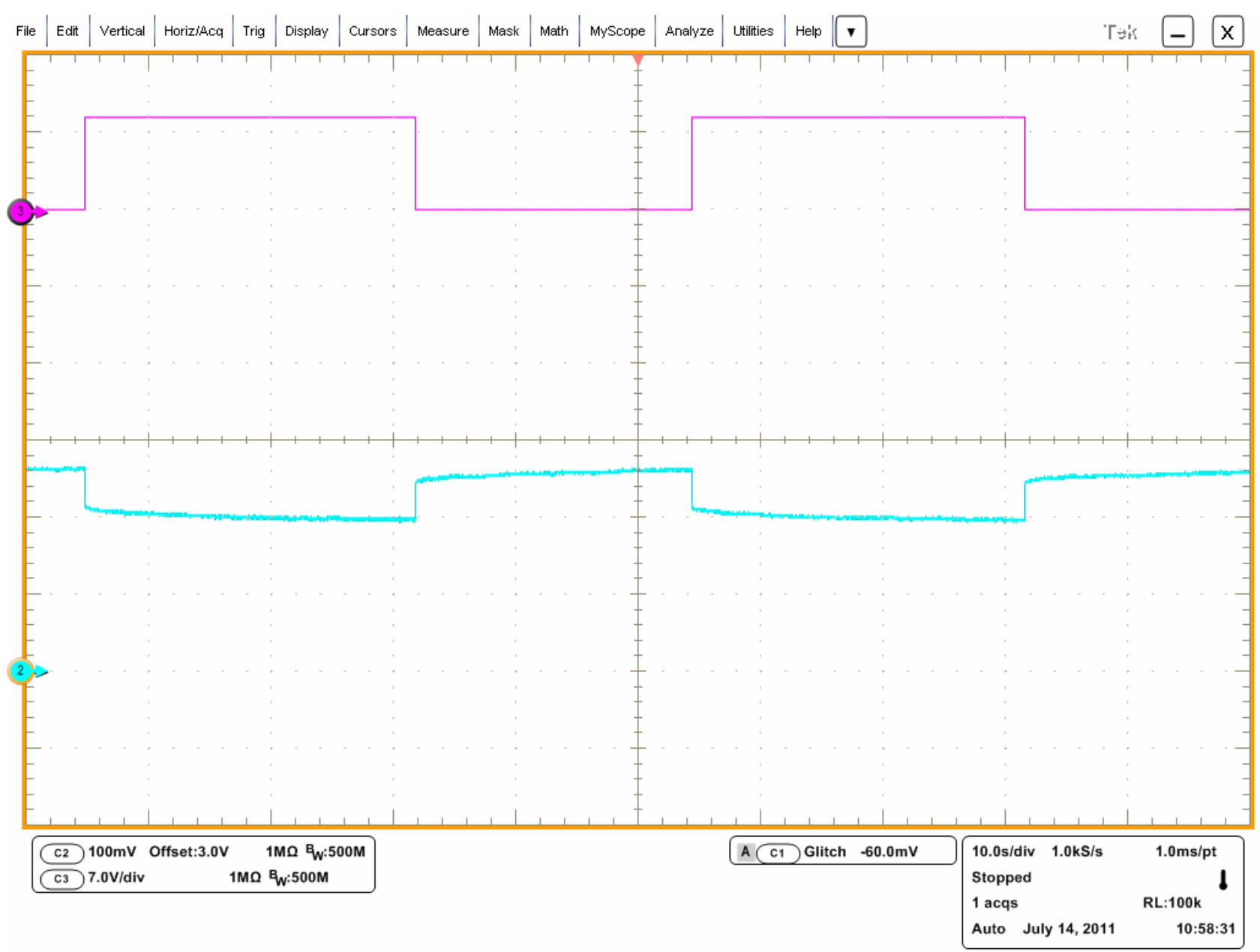

Figure 8. Voltage signals seen by Tektronix DP07354 oscilloscope for 55 A.

The parameters in the proposed model are functions of SOC, current, temperature and cycle number. However, the next tests show that the small error tolerance allows the parameters to be simplified or be independent of some variables. To consider the effect of current upon the battery parameters performance, the voltage difference between the points $\mathrm{A}$ and $\mathrm{B}$ together and points $\mathrm{A}$ and $C$ is measured and referred to current as illustrated in Figure 9. The difference in voltage referred to current between $\mathrm{A}$ and $\mathrm{B}$ represents the battery series resistance $\left(R_{b s}\right)$ in Figure 3 while the difference between $\mathrm{A}$ and $\mathrm{C}$ represents the whole battery impedance. Generally, the actual electric current demand of the electric vehicle varies according to the operating mode such as accelerating, constant speed or decelerating mode. The battery parameters determination may vary according to the discharge current. Therefore, several currents are tested while the other variables are kept fixed. The percentage error evaluation is calculated within the tested current limits.

The effect of current is small especially at higher currents. This is indicated from the close values in milli- ohms of the vertical axis as shown from Figures $\mathbf{1 0}$ and 11. For fixed SOC, the vertical differences in Figures $\mathbf{1 0}$ and $\mathbf{1 1}$ are in the ranges of micro-ohms or fractions of milli-ohm. For instance, considering that SOC equals 1, the vertical difference from Figure 11 between $11 \mathrm{~A}$ and $55 \mathrm{~A}$ is $0.215 \mathrm{~m} \Omega$. Of which about $0.156 \mathrm{~m} \Omega$ relates to the battery series resistance $\left(R_{b s}\right)$ as in Figure 10. This will be translated into errors in ranges of milli-volts at the battery terminals. This would imply that between 11 $\mathrm{A}$ and $55 \mathrm{~A}$, the battery terminal voltage error will be $9.46 \mathrm{mV}(44 \mathrm{~A} \times 0.215 / 1000)$. If this value is referred to $3.3 \mathrm{~V}$ from Table 1, then the error evaluation will be $0.287 \%(100 \times 9.46 \mathrm{mV} / 3.3)$. The estimated error difference between $11 \mathrm{~A}$ and $55 \mathrm{~A}$ for various SOC values is given in Table 2. This indicates that the parameters are approximately independent of the discharging currents. Also at higher values of battery SOC as in Figures $\mathbf{1 0}$ and 11, the corresponding values of the impedances are approximately fixed for a specified current. This current characteristics behavior simplifies the modeling procedures. The effect of current upon the individual parameters will be checked in the next section. 
Table 2. Percentage error evaluation due to current variation.

\begin{tabular}{cccc}
\hline SOC & $\begin{array}{c}\text { Difference between } \\
\text { points A and } \mathrm{C}(\mathrm{m} \Omega)\end{array}$ & $\begin{array}{c}\text { Absolute error } \\
(\mathrm{mV})\end{array}$ & $\begin{array}{c}\text { Percentage } \\
\text { error }(\%)\end{array}$ \\
\hline 0.2 & 0.333 & 14.65 & 0.44 \\
0.3 & 0.2 & 7.92 & 0.24 \\
0.4 & 0.23 & 10.12 & 0.306 \\
0.512 & 0.22 & 9.68 & 0.293 \\
0.68 & 0.2 & 8.89 & 0.269 \\
0.78 & 0.21 & 9.55 & 0.289 \\
1 & 0.215 & 9.46 & 0.287 \\
\hline
\end{tabular}

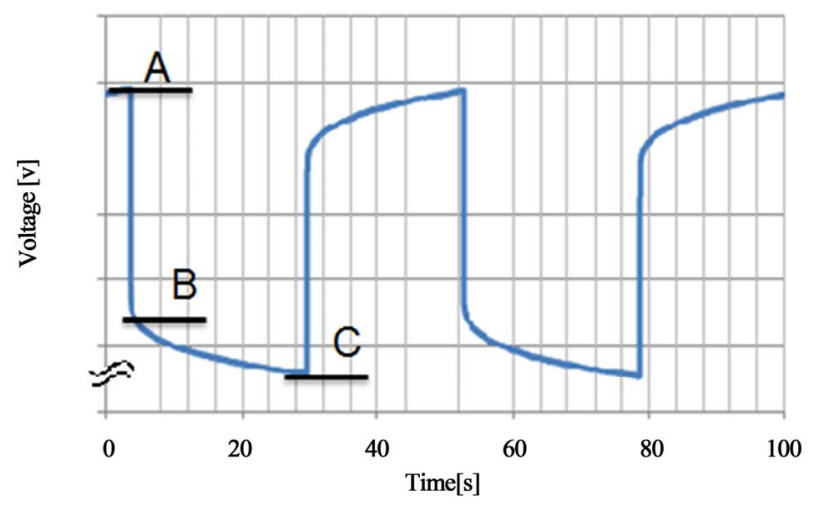

Figure 9. Typical battery response waveform.

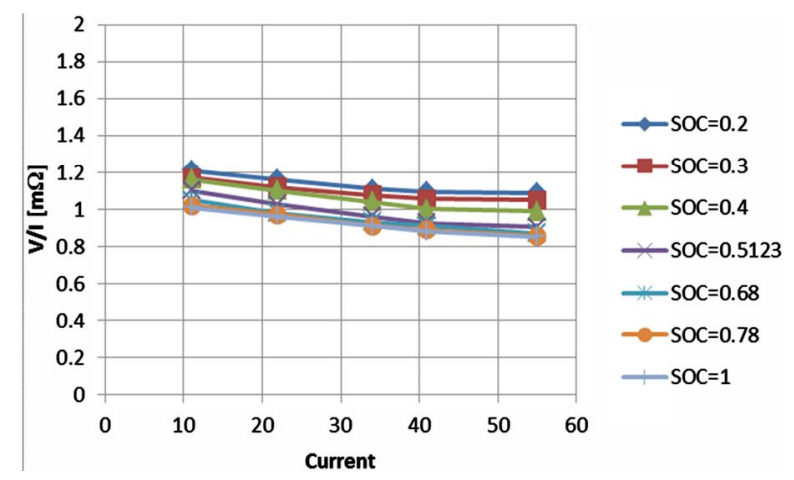

Figure 10. Measured voltage difference between A and B referred to current.

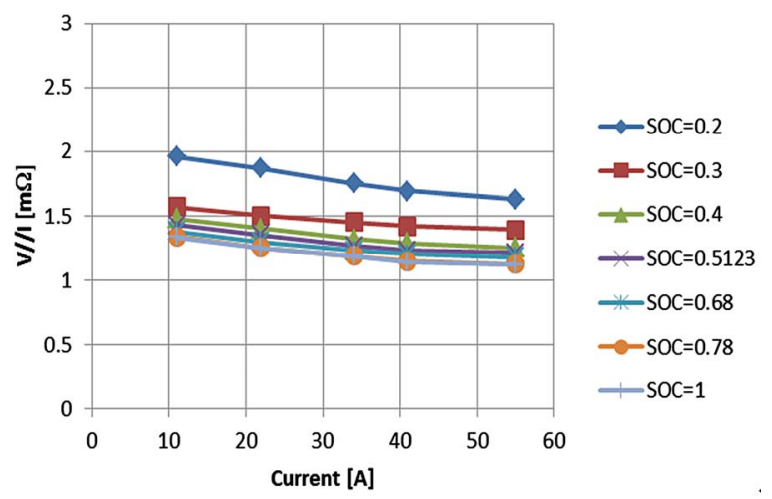

Figure 11. Measured voltage difference between $A$ and $C$ referred to current.
Moreover in [1], it is referred that the capacity tests done with a prismatic type battery having the same specifications as the battery examined in this section showed that the tested cells still had a full capacity after 50 cycles. Also for repetitively or frequently used batteries, the monthly self-discharge can be ignored.

While stacking, the experimented battery bank cells are placed in series. To consider this effect of stacking on the battery bank, the battery internal resistance is calculated for the chosen cell, three series cells, five cells and total number of cells in the bank. These numbers are chosen to decrease the error in measurements and calculations. The analytical method used to calculate the battery internal resistance is explained in Appendix A for one cell. The method is expanded for the series connected cells. The results are shown in Table 3 . Considering a specific current, it was found that the mean values of the battery internal resistance $R_{b s}$ of the series connected cells are close to each other. As the actual power demand of EV varies with the operating mode, therefore a dynamic current of $55 \mathrm{~A}$, which is close to the actual discharge current, is selected to calculate the battery internal resistances. For instance with SOC equals 1, the error difference between one cell and the mean of three cells is $0.05 \mathrm{~m} \Omega$. The first cell terminal voltage error difference with respect to the mean value of the three cells will be $2.75 \mathrm{mV}(0.05 \mathrm{~m} \Omega \times 55 \mathrm{~A})$. Considering the mean values of the battery internal resistance per SOC value of the figures of Table $\mathbf{3}$ and the error differences between the mean values and the chosen cell internal resistance, which are given in Table 4, it can be concluded that the battery cells characteristics are very close to each other.

Such characteristics of this prismatic type LiFePO4 battery simplify the modeling procedures. Therefore, one cell is used to extract the model and its model will be applied to other cells from the same manufacturer.

Table 3. Effect of staking on the battery internal resistance.

\begin{tabular}{|c|c|c|c|c|}
\hline \multirow{2}{*}{$\mathrm{SOC}$} & \multicolumn{4}{|c|}{ Rbs for $55 \mathrm{~A}(\mathrm{~m} \Omega)$} \\
\hline & One cell & Three cells & Five cells & 30 cells \\
\hline 0.2 & 1.084 & $\begin{array}{c}3.183 \\
\text { Mean }=1.061\end{array}$ & $\begin{array}{c}5.133 \\
\text { Mean }=1.027\end{array}$ & $\begin{array}{c}31.64 \\
\text { Mean }=1.054\end{array}$ \\
\hline 0.3 & 1.052 & $\begin{array}{c}3.1 \\
\text { Mean }=1.033\end{array}$ & $\begin{array}{c}4.85 \\
\text { Mean }=0.97\end{array}$ & $\begin{array}{c}30.75 \\
\text { Mean }=1.025\end{array}$ \\
\hline 0.4 & 0.95 & $\begin{array}{c}2.9464 \\
\text { Mean }=0.982\end{array}$ & $\begin{array}{c}4.225 \\
\text { Mean }=0.845\end{array}$ & $\begin{array}{c}28.57 \\
\text { Mean }=0.95\end{array}$ \\
\hline 0.51 & 0.89 & $\begin{array}{c}2.9324 \\
\text { Mean }=0.977\end{array}$ & $\begin{array}{c}4.22 \\
\text { Mean }=0.844\end{array}$ & $\begin{array}{c}27.23 \\
\text { Mean }=0.91\end{array}$ \\
\hline 0.78 & 0.86 & $\begin{array}{c}2.82 \\
\text { Mean }=0.94\end{array}$ & $\begin{array}{c}4.22 \\
\text { Mean }=0.844\end{array}$ & $\begin{array}{c}27.18 \\
\text { Mean }=0.91\end{array}$ \\
\hline 1 & 0.86 & $\begin{array}{c}2.73 \\
\text { Mean }=0.91\end{array}$ & $\begin{array}{c}4.21 \\
\text { Mean }=0.842\end{array}$ & $\begin{array}{c}27.17 \\
\text { Mean }=0.91\end{array}$ \\
\hline & Mean & calculated va & le/number of ce & \\
\hline
\end{tabular}


Table 4. Absolute value of the internal resistance error difference between one cell and the mean of 3,5 and 30 cells in series.

\begin{tabular}{cccc}
\hline SOC & $\begin{array}{c}\text { Error difference } \\
\text { between one cell } \\
\text { internal resistance } \\
\text { and the mean of 3 } \\
\text { cells }(\mathrm{m} \Omega)\end{array}$ & $\begin{array}{c}\text { Error difference } \\
\text { between one cell } \\
\text { internal } \\
\text { resistance and the } \\
\text { mean of 5 cells } \\
(\mathrm{m} \Omega)\end{array}$ & $\begin{array}{c}\text { Error difference } \\
\text { between one cell } \\
\text { internal } \\
\text { resistance and the } \\
\text { mean of 30 cells } \\
(\mathrm{m} \Omega)\end{array}$ \\
\hline 0.2 & 0.023 & 0.057 & 0.03 \\
0.3 & 0.019 & 0.082 & 0.027 \\
0.4 & 0.032 & 0.105 & 0 \\
0.51 & 0.087 & 0.046 & 0.02 \\
0.78 & 0.08 & 0.016 & 0.05 \\
1 & 0.05 & 0.018 & 0.05 \\
\hline
\end{tabular}

\section{Model Extraction}

In general, Open circuit voltage varies according to SOC, temperature and current. It is important to find the nonlinear relation between the open circuit voltage and SOC for complete modeling. The ambient temperature degrees are kept close to each other. For each SOC point, the measurement of the open circuit voltage can take days. However, the effect of current upon the open circuit voltage $\left(E_{o c}\right)$, which is the voltage at point A of Figure 9, is checked first for the same SOC points of Figures 10 and 11. The results are illustrated in Figure 12. Small open circuit voltage differences among the discharge currents indicate that the open circuit voltage is approximately independent of the tested discharge currents. Therefore, the dynamic current will be tested carefully at very high and very low SOC values in order to extract the open circuit voltage as a function of SOC.

For several days, the chosen cell open circuit voltage is measured at different SOC values and the fixed dynamic current as shown in Table 5. The temperature of the battery measured by the production company BMS is similar to the ambient in all readings. The temperature readings are $26^{\circ} \mathrm{C}$ for all readings except for SOC equals 0.78 , in which the temperature is $27^{\circ} \mathrm{C}$. For SOC lower than 0.3 , the battery open circuit voltage decreases exponentially. For medium and high values of SOC, the open circuit voltage increases linearly with small slope. For very high values of SOC, the open circuit voltage increases with some non-linearity in the measured voltage. The next function given in Equation (5) is used to fit the empirical data of Table 5. Table 6 gives percenttage error between the fitted values and the measured data.

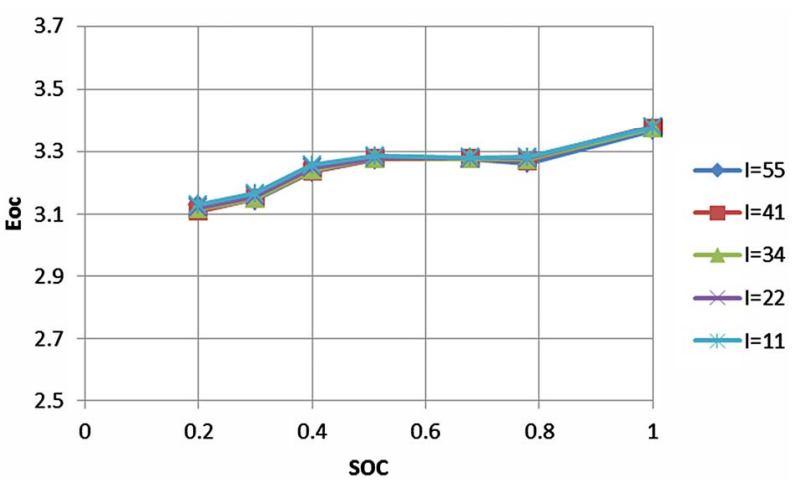

Figure 12. Effect of current upon the open circuit voltage.

Table 5. Battery open circuit voltage verus SOC at 55 A.

\begin{tabular}{cc}
\hline SOC & Measured voltage $(\mathrm{V})$ \\
\hline 0.18 & 3.0936 \\
0.2 & 3.129 \\
0.3 & 3.1569 \\
0.4 & 3.2352 \\
0.51 & 3.275 \\
0.68 & 3.2764 \\
0.78 & 3.2622 \\
0.85 & 3.27 \\
0.88 & 3.290 \\
0.93 & 3.3 \\
0.96 & 3.367 \\
1 & 3.38 \\
\hline
\end{tabular}

Table 6. Percentage error between measured and fitted voltage.

\begin{tabular}{ccccc}
\hline SOC & $\begin{array}{c}\text { Measured } \\
\text { voltage (V) }\end{array}$ & $\begin{array}{c}\text { Fitted } \\
\text { voltage (V) }\end{array}$ & $\begin{array}{c}\text { Absolute error } \\
(\mathrm{mV})\end{array}$ & $\begin{array}{c}\text { Percentage } \\
\text { error }(\%)\end{array}$ \\
\hline 0.18 & 3.0936 & 3.1024 & 8.8 & 0.2844 \\
0.2 & 3.129 & 3.1605 & 31.5 & 1.1 \\
0.3 & 3.1569 & 3.2191 & 62.2 & 1.97 \\
0.4 & 3.2352 & 3.2302 & 5 & 0.1545 \\
0.51 & 3.275 & 3.239 & 36 & 1.09 \\
0.68 & 3.2764 & 3.2535 & 22.54 & 0.697 \\
0.78 & 3.2622 & 3.2618 & 0.33 & 0.01 \\
0.85 & 3.27 & 3.267 & 3 & 0.09 \\
0.88 & 3.29 & 3.27 & 0.02 & 0.6 \\
0.93 & 3.3 & 3.274 & 0.026 & 0.78 \\
0.96 & 3.367 & 3.315 & 0.052 & 1.54 \\
1 & 3.38 & 3.352 & 0.028 & 0.83 \\
\hline
\end{tabular}

$$
E_{o c}=\left\{\begin{array}{l}
-0.92 \mathrm{e}^{-11 \mathrm{SOC}}+3.197+0.188 \mathrm{SOC}-0.0999 \mathrm{SOC}^{2}+0.32 \mathrm{SOC}^{3} \text { for } \mathrm{SOC}<0.3 \\
3.197+0.08317 \mathrm{SOC} \text { for } 0.3<\mathrm{SOC}<0.95 \\
3.4-1.06583 \mathrm{SOC}+1.018 \mathrm{SOC}^{2} \text { for } \mathrm{SOC}>0.95
\end{array}\right\}
$$


Considering the experimental tests of Section 3, The $\mathrm{RC}$ networks values as functions of SOC can be extracted. Figure 10 directly represents the battery internal resistance $\left(R_{b s}\right)$. It is redrawn in Figure 13 with SOC in the $\mathrm{x}$-axis. The method used to find the parameters of the battery is explained in Appendix A for fixed SOC and temperature. Figures 14-17 represent the short term and long term time constants resistances and capacitances.

Away from the long term time constant capacitance,

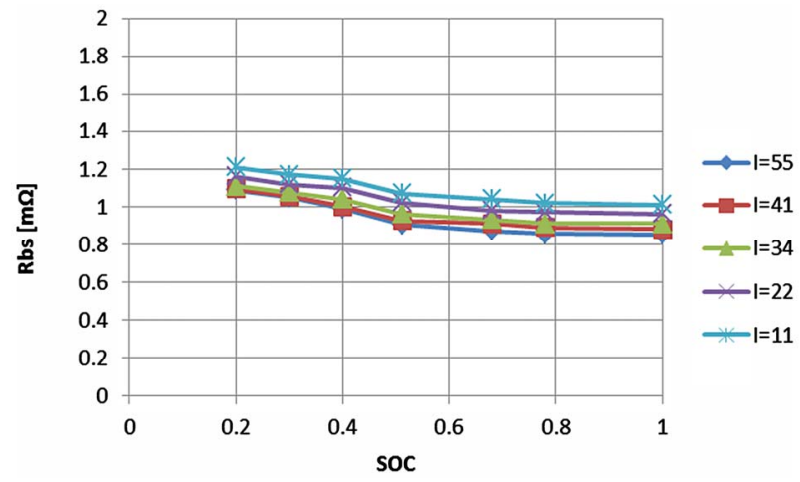

Figure 13. Battery internal resistance as a function of SOC.

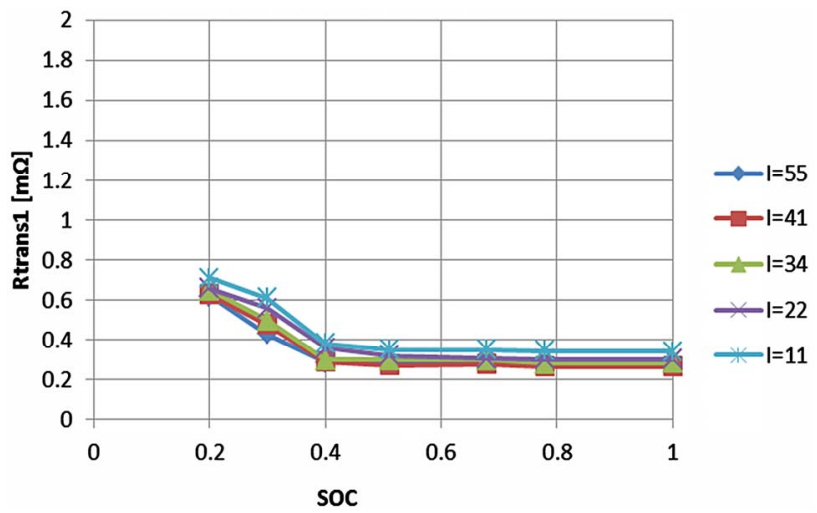

Figure 14. Short term time constant resistance as a function of SOC.

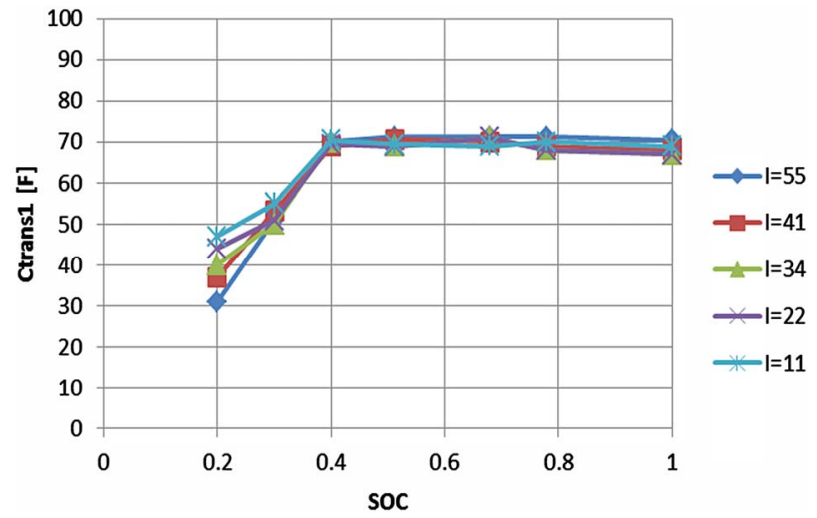

Figure 15. Short term time constant capacitance as a function of SOC.

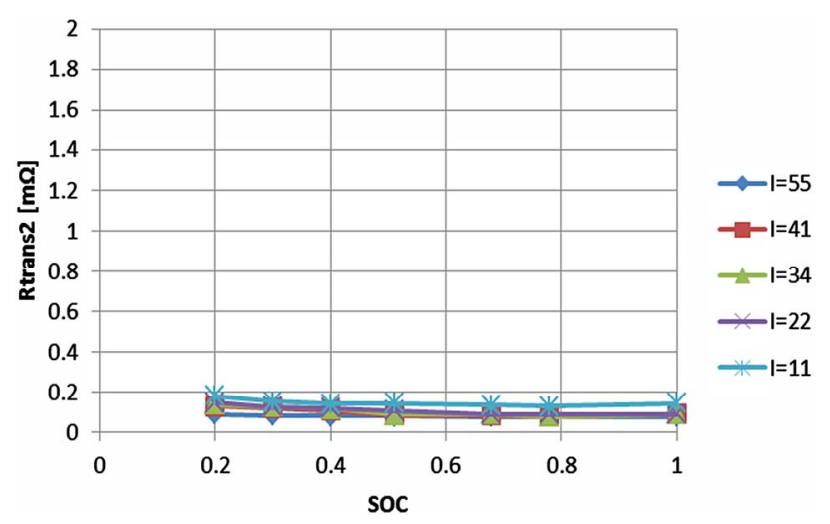

Figure 16. Long term time constant resistance as a function of SOC.

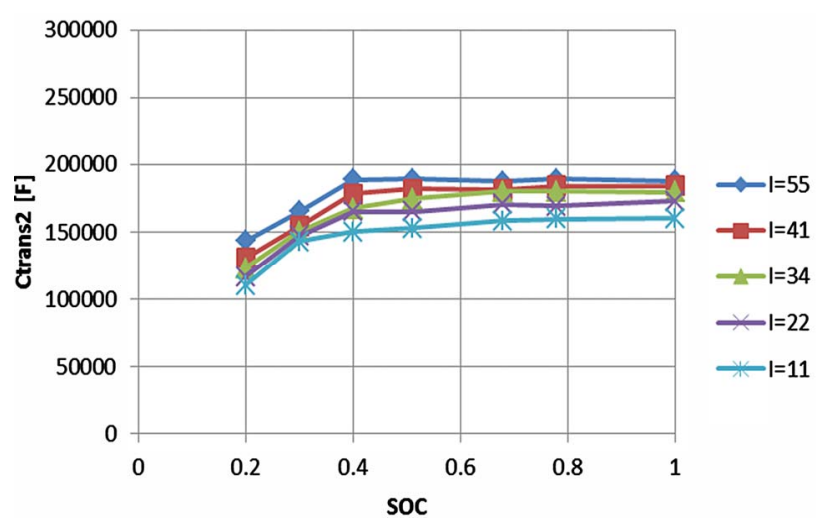

Figure 17. Long term time constant capacitance as a function of SOC.

current has very slight effect on the parameter determination. Therefore, a dynamic current for the electric power demand close to the actual discharge current should be selected to extract the parameters to find single-variable curves. Even though averaging technique can be used for the long term time constant capacitance, however the error evaluation of the currents close to the dynamic current will be checked in the next section to prove the validity of the single variable curves. Moreover by investigating Figures 13-17, the parameter values of the currents near the dynamic current are very close to each other. From Figures 18 to 22, the calculated values from measurements are drawn by an asterisk and the best-fitted curves are drawn by a continuous red color. All the extracted parameters are fixed in the region from $40 \%$ to $100 \%$ SOC. Using the curve fitting method to these empirical data, the following functions are used to represent these curves:

$$
\begin{aligned}
& R_{b s}(\mathrm{SOC})=1.3-1.2 \mathrm{SOC}+1.1 \mathrm{SOC}^{2}-0.33 \mathrm{SOC}^{3} \\
& R_{\text {trans }}(\mathrm{SOC})= 2-10.554 \mathrm{SOC}+22.604 \mathrm{SOC}^{2} \\
&-20.59 \mathrm{SOC}^{3}+7.1067 \mathrm{SOC}^{4}
\end{aligned}
$$




$$
\begin{aligned}
& C_{\text {trans } 1}(\mathrm{SOC})=-110+940 \mathrm{SOC}-1800 \mathrm{SOC}^{2} \\
& +1500 \mathrm{SOC}^{3}-460 \mathrm{SOC}^{4} \\
& R_{\text {trans } 2}(\mathrm{SOC})=0.13-0.28 \mathrm{SOC}+0.6 \mathrm{SOC}^{2} \\
& -0.56 \mathrm{SOC}^{3}+0.19 \mathrm{SOC}^{4} \\
& C_{\text {trans } 2}(\mathrm{SOC})=\left(-9.19+1020.3 \mathrm{SOC}-1829.7 \mathrm{SOC}^{2}\right. \\
& \left.+1361.2 \mathrm{SOC}^{3}-354.54 \mathrm{SOC}^{4} \times 1000\right)
\end{aligned}
$$

In order to check the voltage behavior of the extracted model during the rest time, the simulated results according to Equations from (5) to (10) and the corresponding experimental results are shown from Figures 23 to $\mathbf{2 7}$ for SOC equals 0.78 . The rest time is the time corresponding to the off-period. Even though the model is extracted at the dynamic current, however the close agreement between the experimental and simulated results proves that the above equations can be used during the rest time to describe the battery behavior.

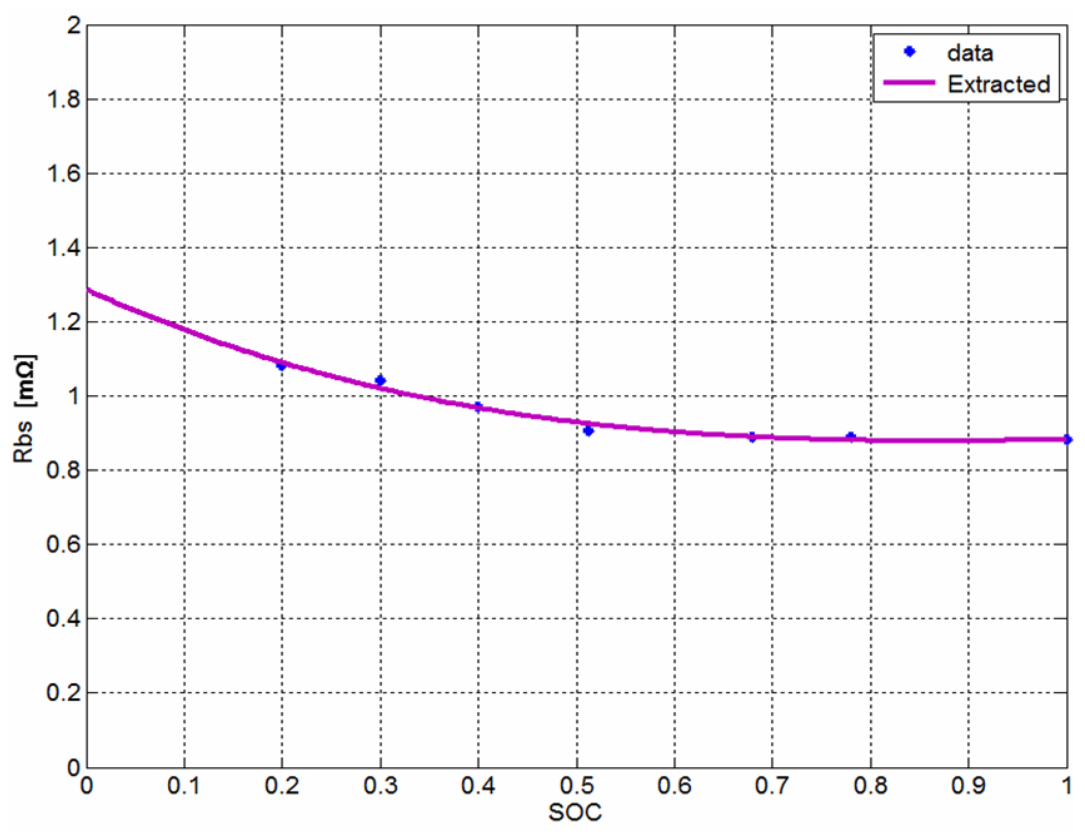

Figure 18. Extracted battery internal resistance.

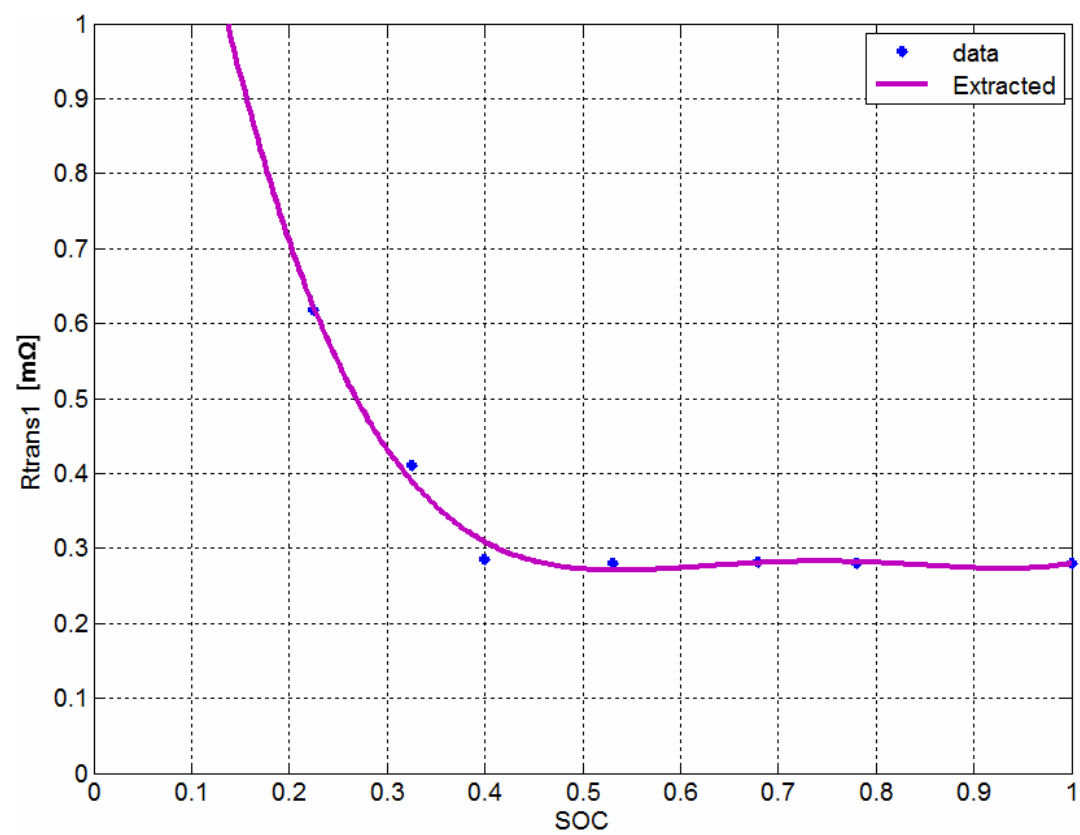

Figure 19. Extracted short term time constant resistance. 


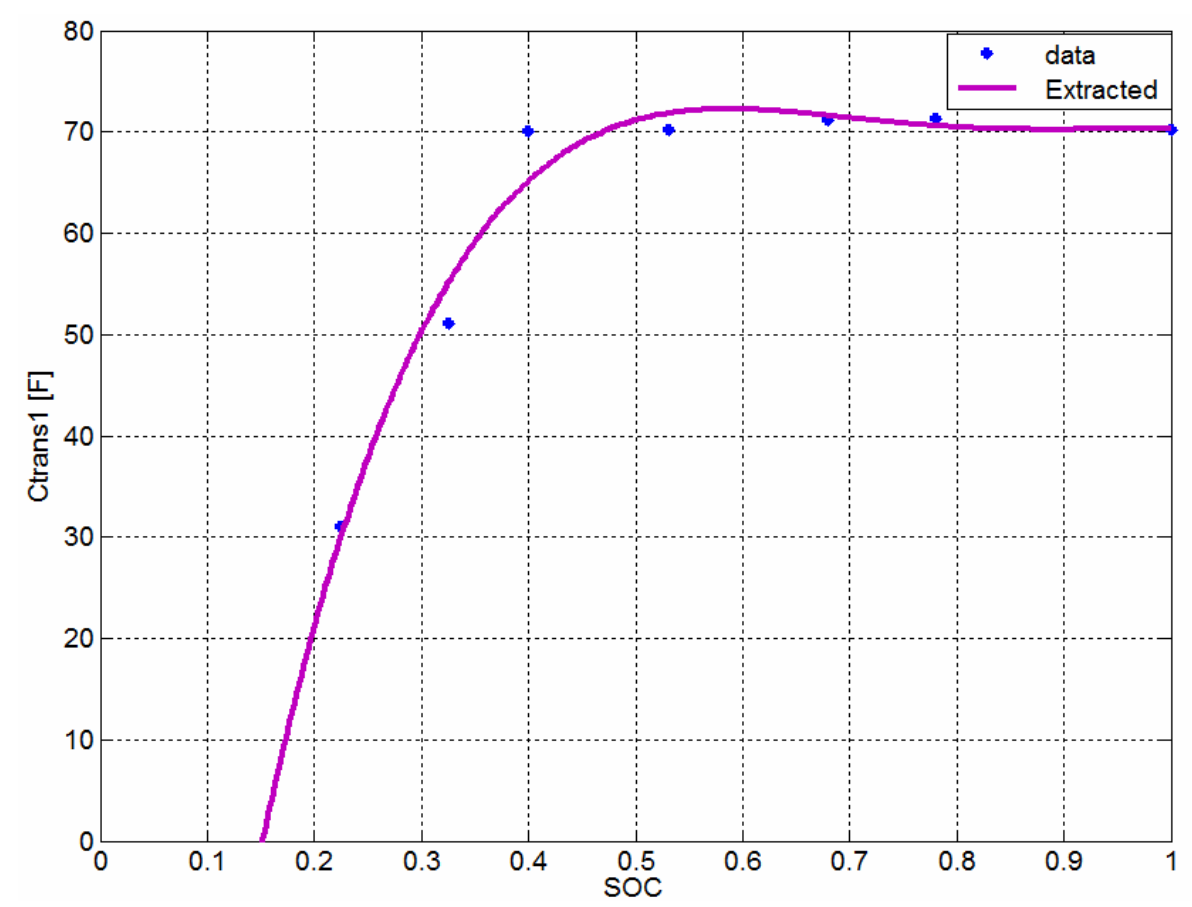

Figure 20. Extracted short term time constant capacitance.

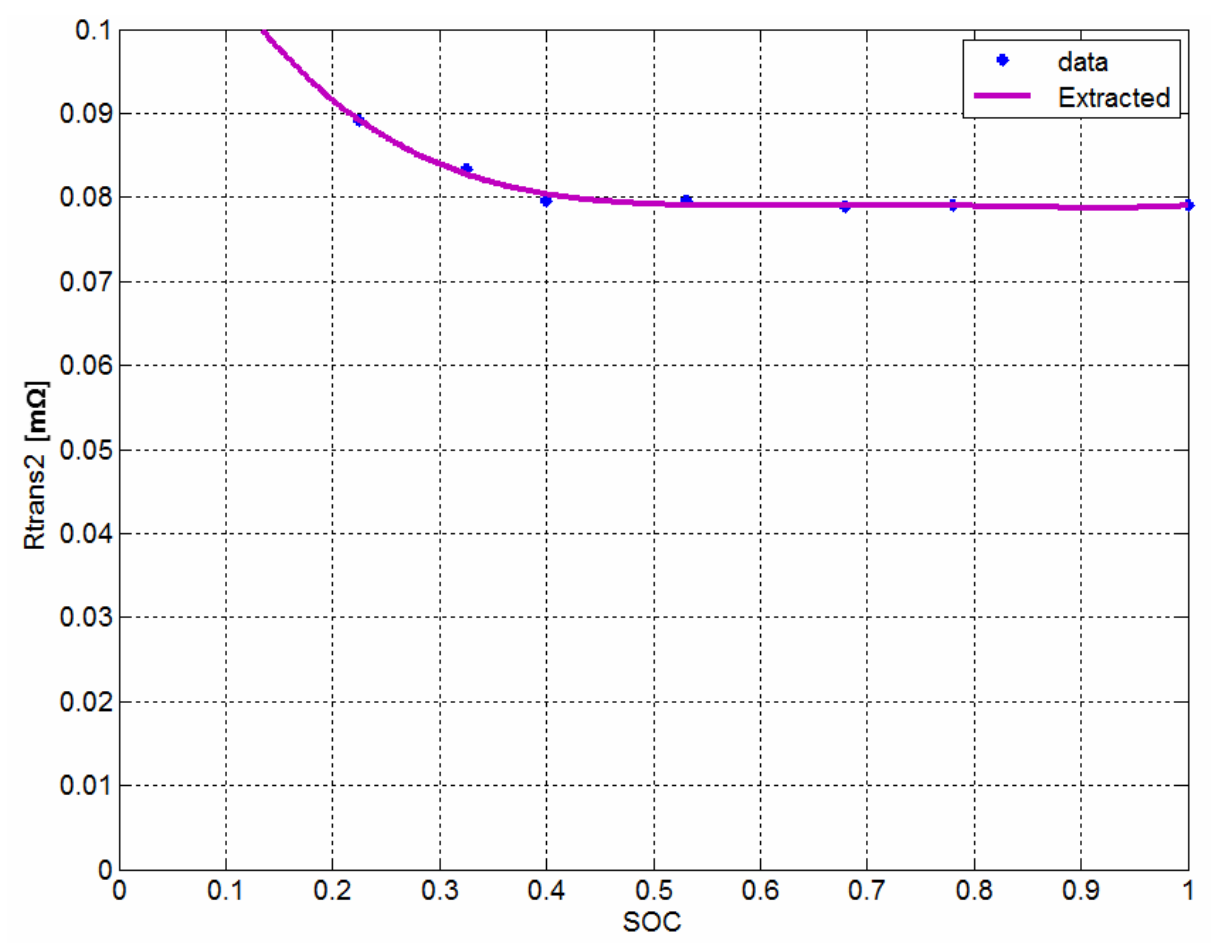

Figure 21. Extracted long term time constant resistance.

From the experiments done with LFP battery and extracted parameters, some observations are found. First, all the resistive elements increase with SOC lower than 0.4. Also, all the capacitive elements decrease with SOC lower than 0.4 . This means when the battery near flat, its resistive elements are more dominant than capacitive parameters and hence it will be sensitive for the discharging currents. The battery internal resistance $R_{b s}$ is related to the current flowing through the metal connectors, plates and electrolyte. This appears clearly because the voltage drop across it changes with current as shown in Figure 28 for two different currents. Short term time 


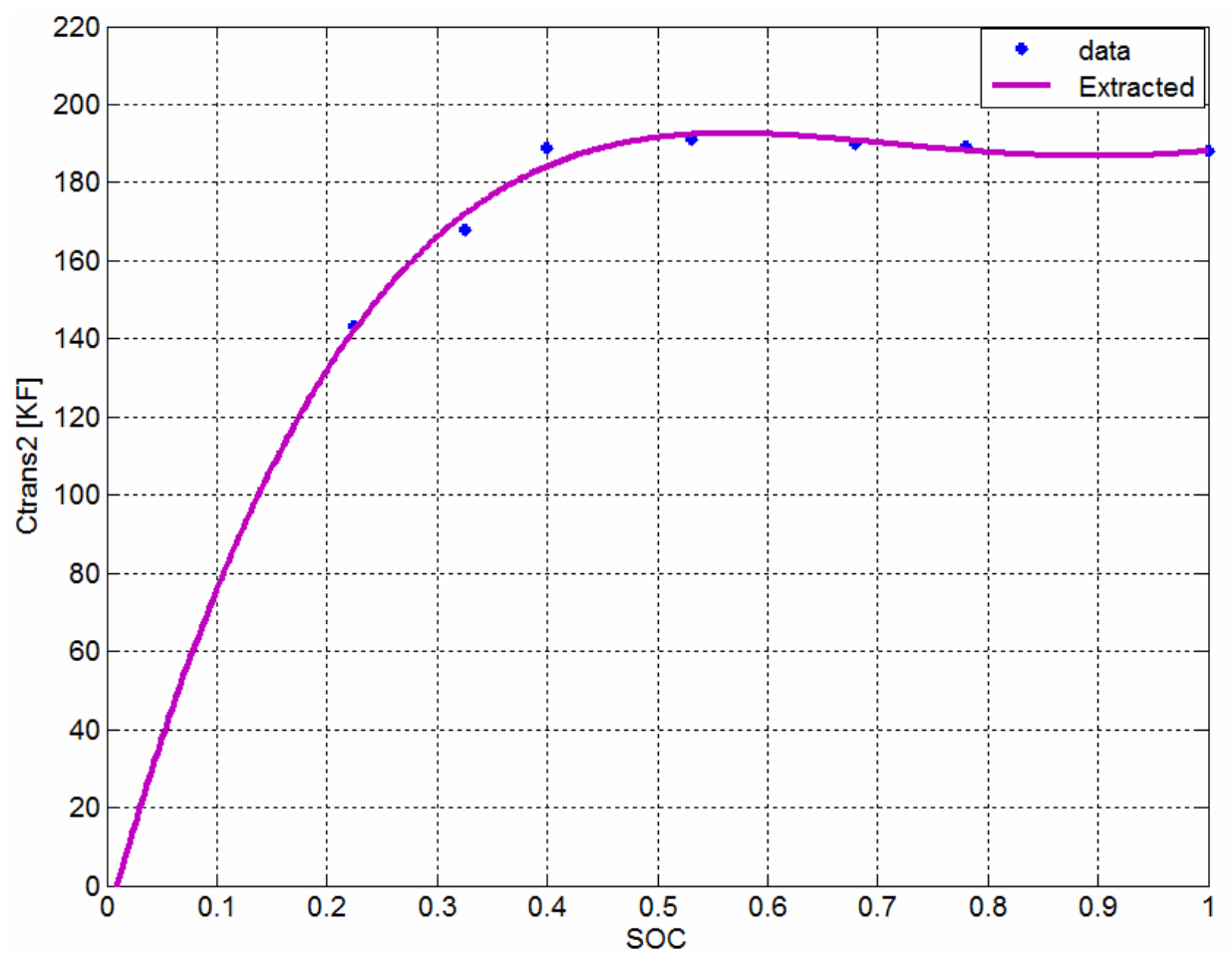

Figure 22. Extracted long term time constant capacitance.

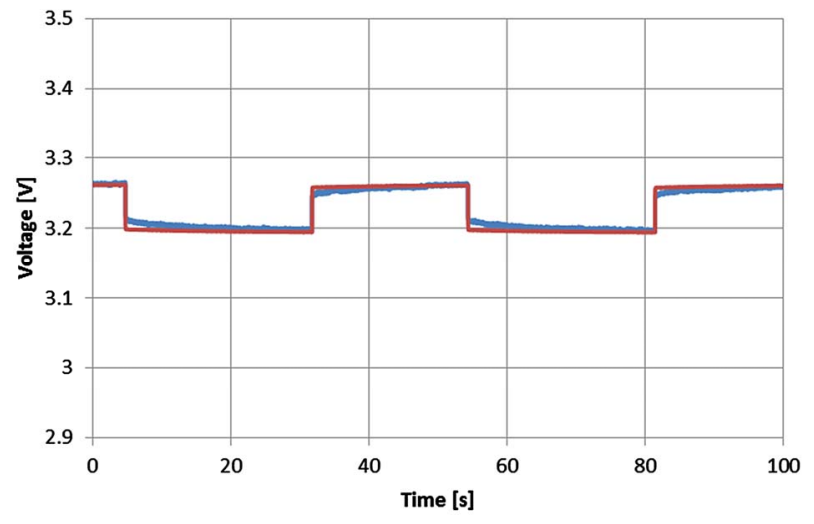

Figure 23. Voltage profile with SOC $=0.78$ and $\mathrm{I}=55 \mathrm{~A}$ [Blue: experimental, red: simulated].

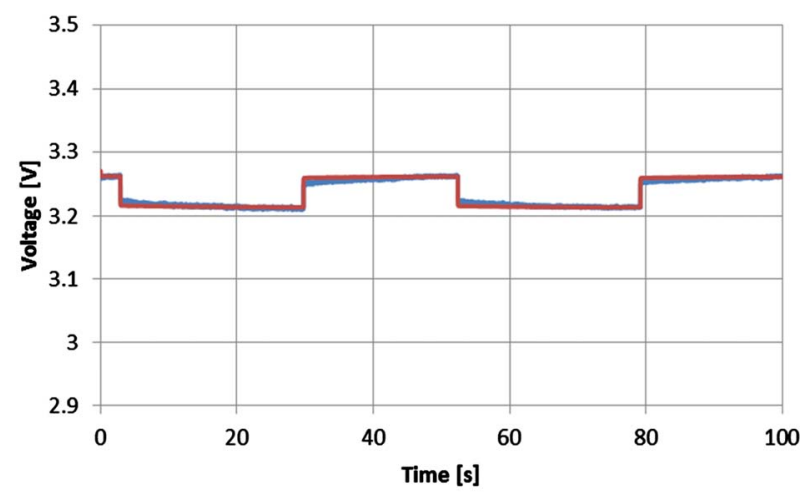

Figure 24. Voltage profile with SOC $=0.78$ and $\mathrm{I}=41 \mathrm{~A}$ [Blue: experimental, red: simulated].

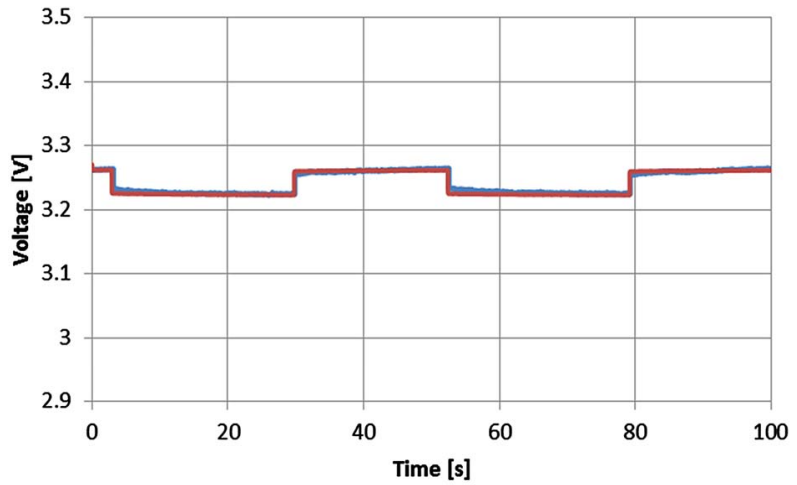

Figure 25. Voltage profile with SOC $=0.78$ and $\mathrm{I}=34 \mathrm{~A}$ [Blue: experimental, red: simulated].

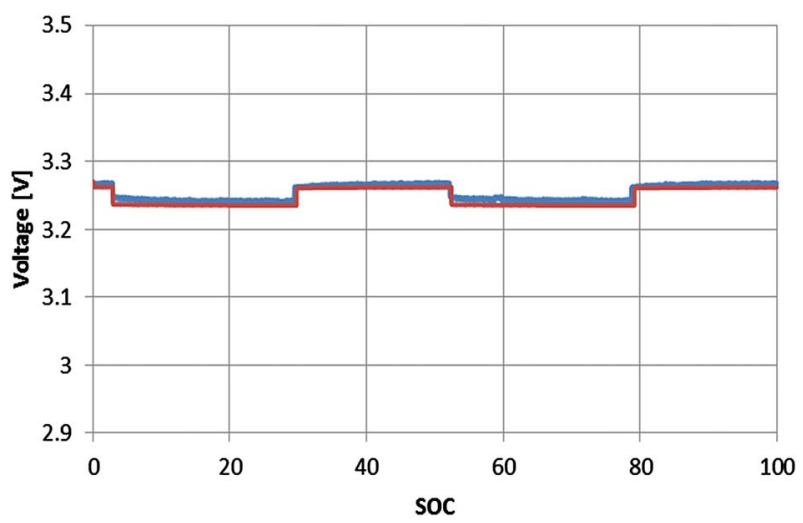

Figure 26. Voltage profile with $\mathrm{SOC}=0.78$ and $\mathrm{I}=22 \mathrm{~A}$ [Blue: experimental, red: simulated]. 


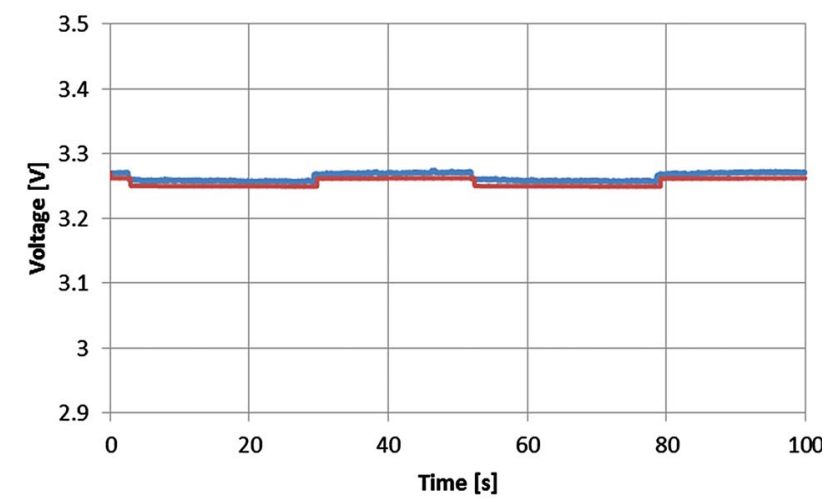

Figure 27. Voltage profile with SOC $=0.78$ and $I=11 \mathrm{~A}$ [Blue: experimental, red: simulated].

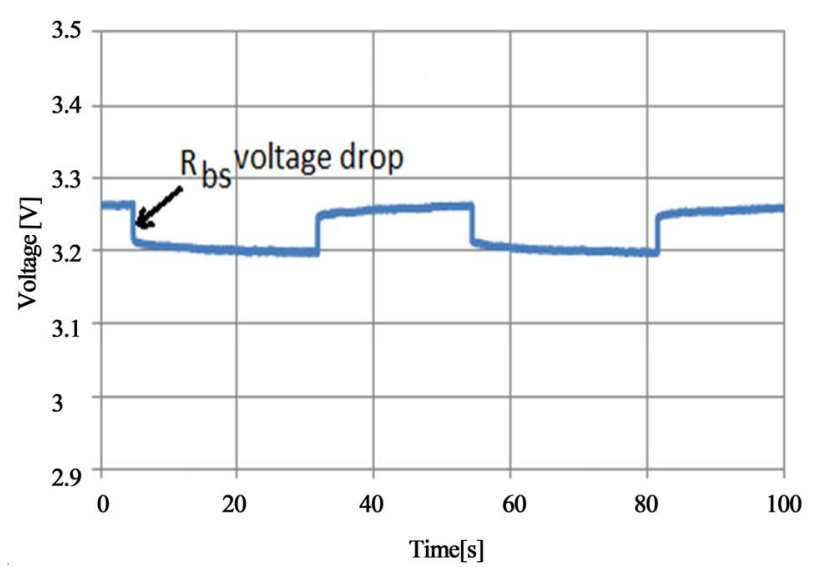

(a)

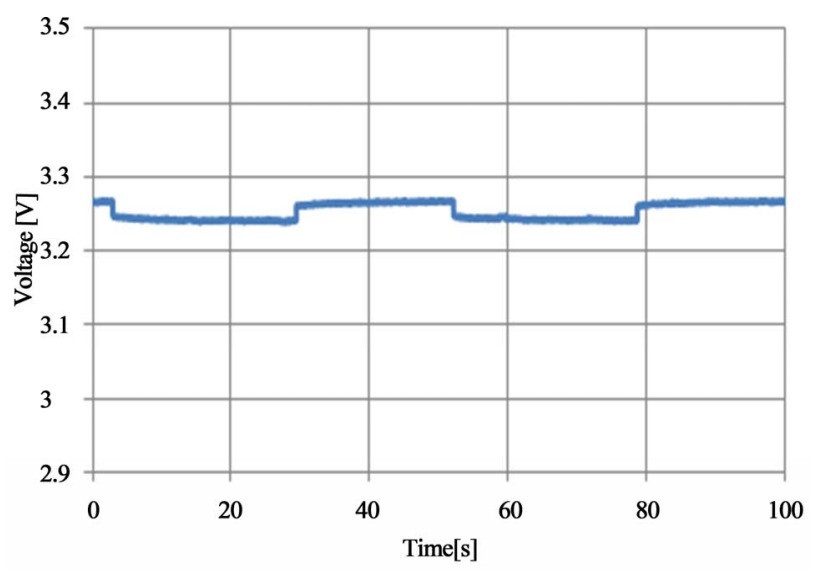

(b)

Figure 28. The Voltage drop across $R_{b s}$ versus current with SOC $=0.78$ (experimental results) [(a): $55 \mathrm{~A}$, (b): $22 \mathrm{~A}]$.

constant can be related to the capacitance, which is related to the permittivity between the two electrodes. This observation comes as a result of the short term time constant capacitance value, which is affected by SOC rather than current. Long term time constant appears to describe the electrochemical reactions in the electrolyte behavior. This is because its related capacitance is affected by the discharging current and SOC. In general, the long term time constant capacitance decreases with reducing the discharging current [12].

\section{Model Validation and Discussion}

After experimentation procedures with TSLFP160AHA bank, the battery is left about 24 hours. The corresponding voltage after that time is called the rest voltage as illustrated in Figure 29. It is observed that the voltage at point A1 (in the first off-period) is lower than the rest voltage. This voltage difference appears to be caused as an effect of current. This overcharge phenomenon is represented by $\left(\alpha \mathrm{e}^{\beta i_{s} t}\right)$ as an addition to Equation (5), in which $\alpha$ is the difference between the rest voltage and point A1 in Figure 29 and $\beta$ is an adaptive parameter. The value of $\alpha$ does not increase under any operating condition than $0.025 \mathrm{~V}$ and $\beta$ is set to 0.0003 to imitate the drop in the voltage profile respectively. This effect is not common in the next off periods after the point A1. Therefore, it can be neglected because it does not affect battery steady state or long term operating performance.

ANSOFT SIMPLORER is a good and simple tool to represent the equivalent circuit of the proposed model. It provides a ready block to implement the algebraic equations directly and the outputs of these equations determine the electrical elements behavior. Moreover, it offers some blocks to implement the mathematical equations that include differentiation or integration.

Considering discharging currents close to the dynamic current, at least for the same manufacturer company, Equations from (5) to (10) are considered general functions for high current healthy prismatic type cells of high power LFP batteries. In order to prove the generality of the extracted model, the GBSLFMP 60 Ah battery bank from the same production company is continuously discharged through a resistive load. From the datasheet of this battery, it has $60 \mathrm{Ah}$ rated capacity. One cell is chosen and its voltage profile is recorded. The discharge test is done when the battery is fully charged up to its final state indicated by an alarm from the BMS system. All the recognized parameters extracted from TSLFP160AHA bank are directly applied to GBSLFMP 60 Ah battery bank. Figure 30 shows the experimental results for $1 \mathrm{C}$ discharging. The same data is compared with the simulated results in Figure 31. In order to investigate the accuracy of Figure 31, a zoomed in image is drawn in Figure 32. The maximum operating time error between the simulated and experimental results is $50 \mathrm{mV}$ with $1.7 \%$ referred to the experimental value and takes place in the exponential zone. Table 7 gives the different accuracy values for different current ranges, which proves the validity of the model. It should be noted that the operating time error percentage in Table $\mathbf{7}$ is the absolute 


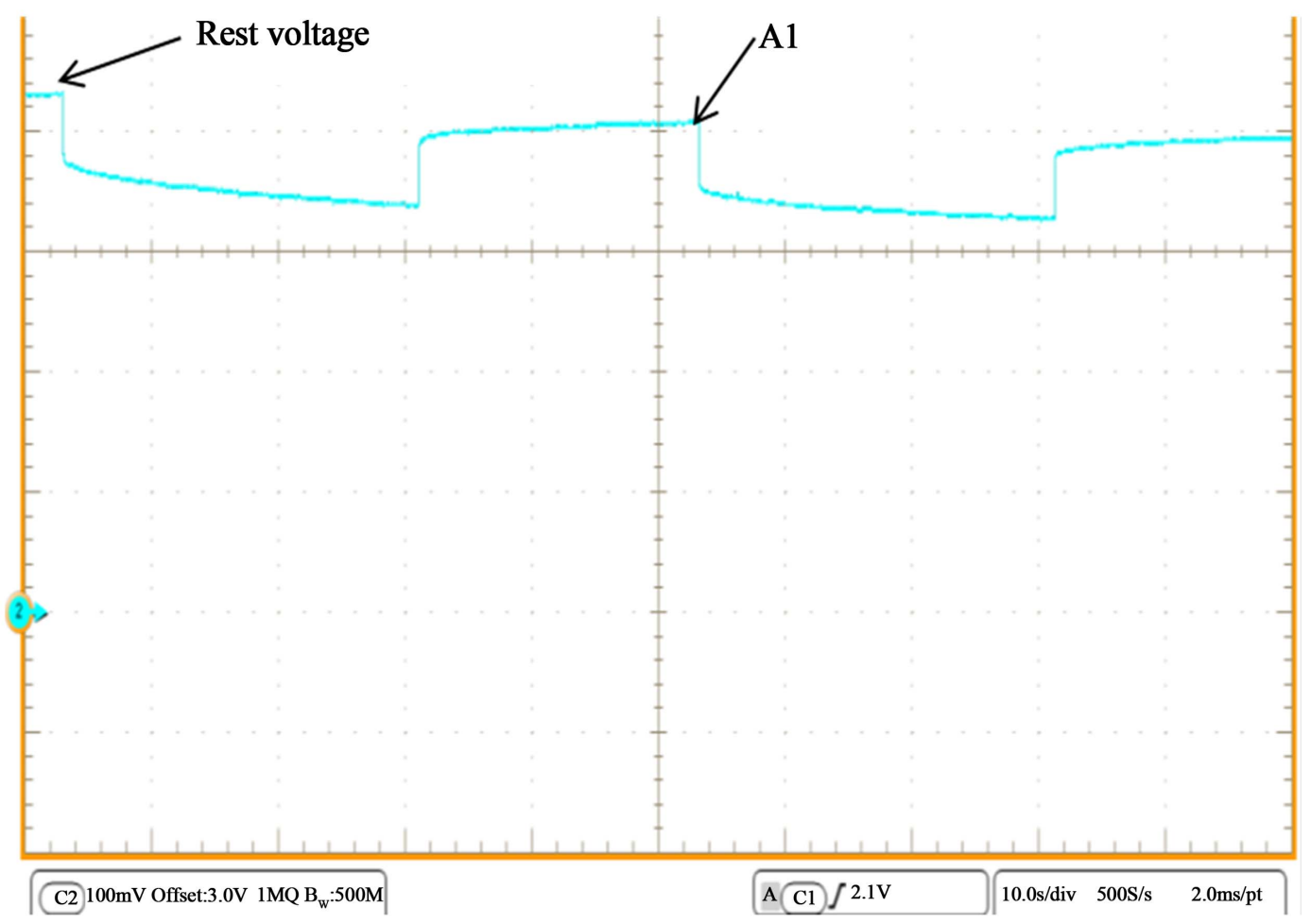

Figure 29. Rest voltage and effect of current.

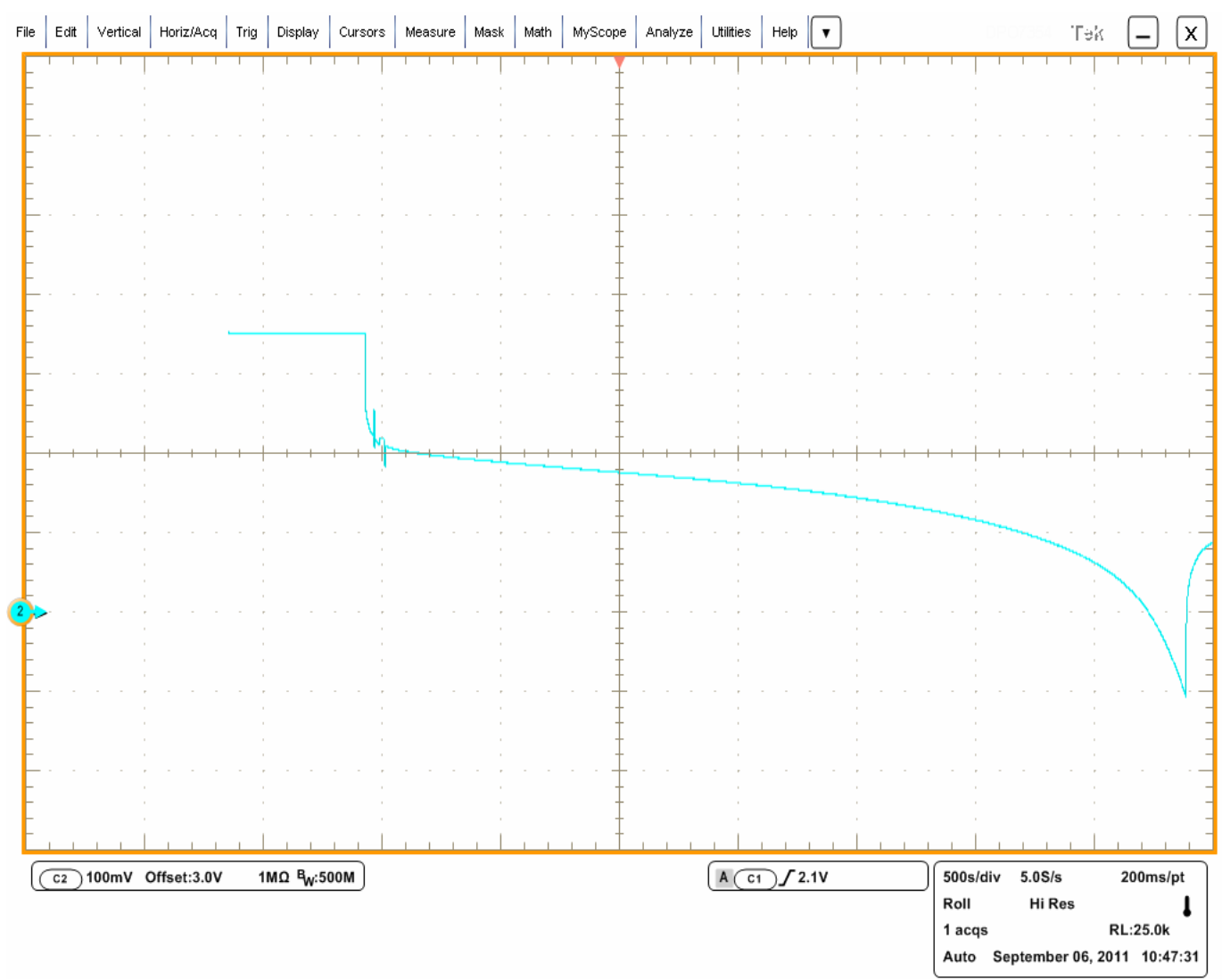

Figure 30. Examination with GBSLFM 60 Ah for $1 \mathrm{C}$ discharging [The arrow starts with $3 \mathrm{~V}, 1$ vertical division = $100 \mathrm{mV}, 1$ horizontal square $=\mathbf{5 0 0} \mathrm{s}]$. 


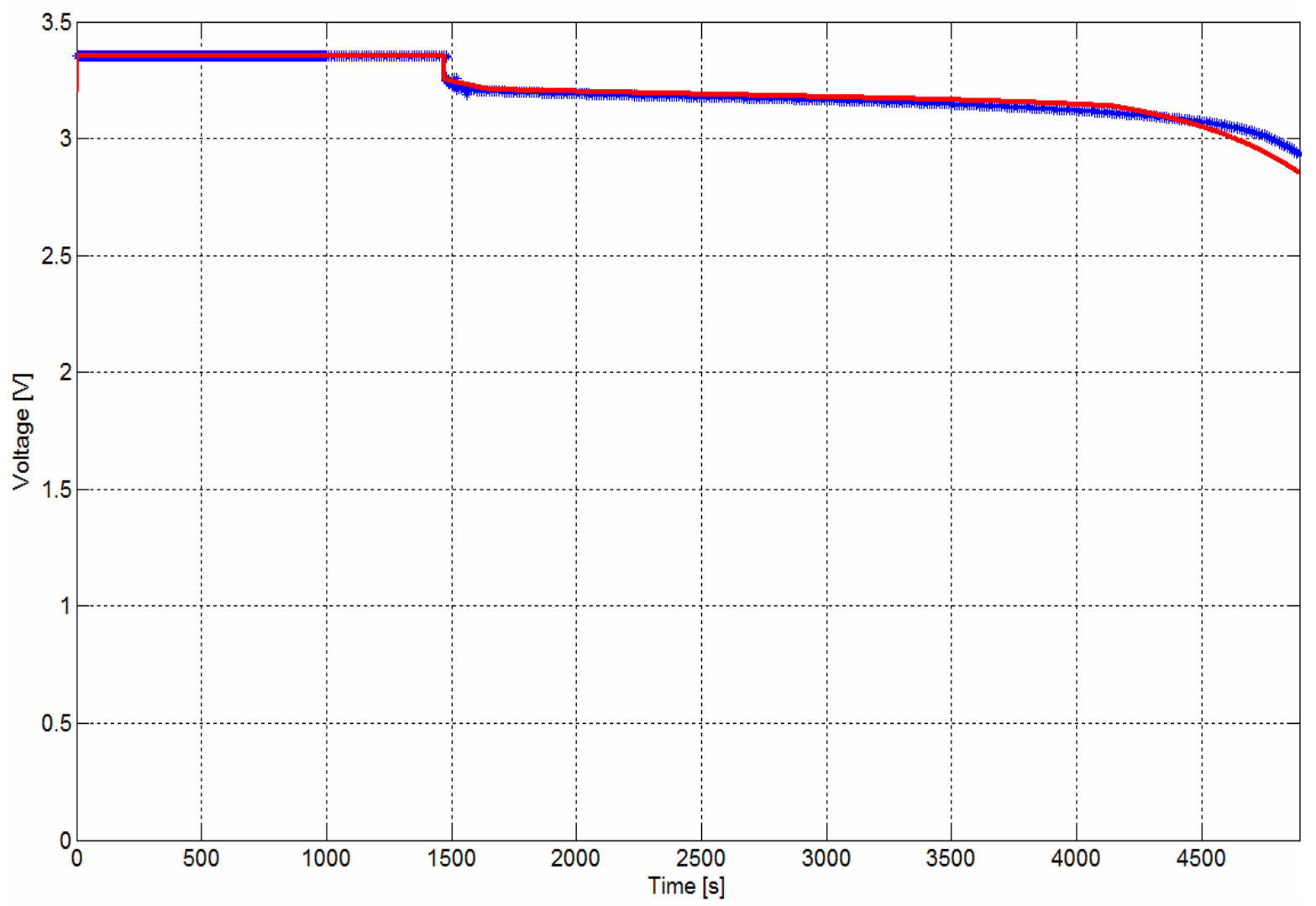

Figure 31. Voltage profile with GBSLFMP 60 AH for 1 C discharging [Blue: experimental, red: simulated].

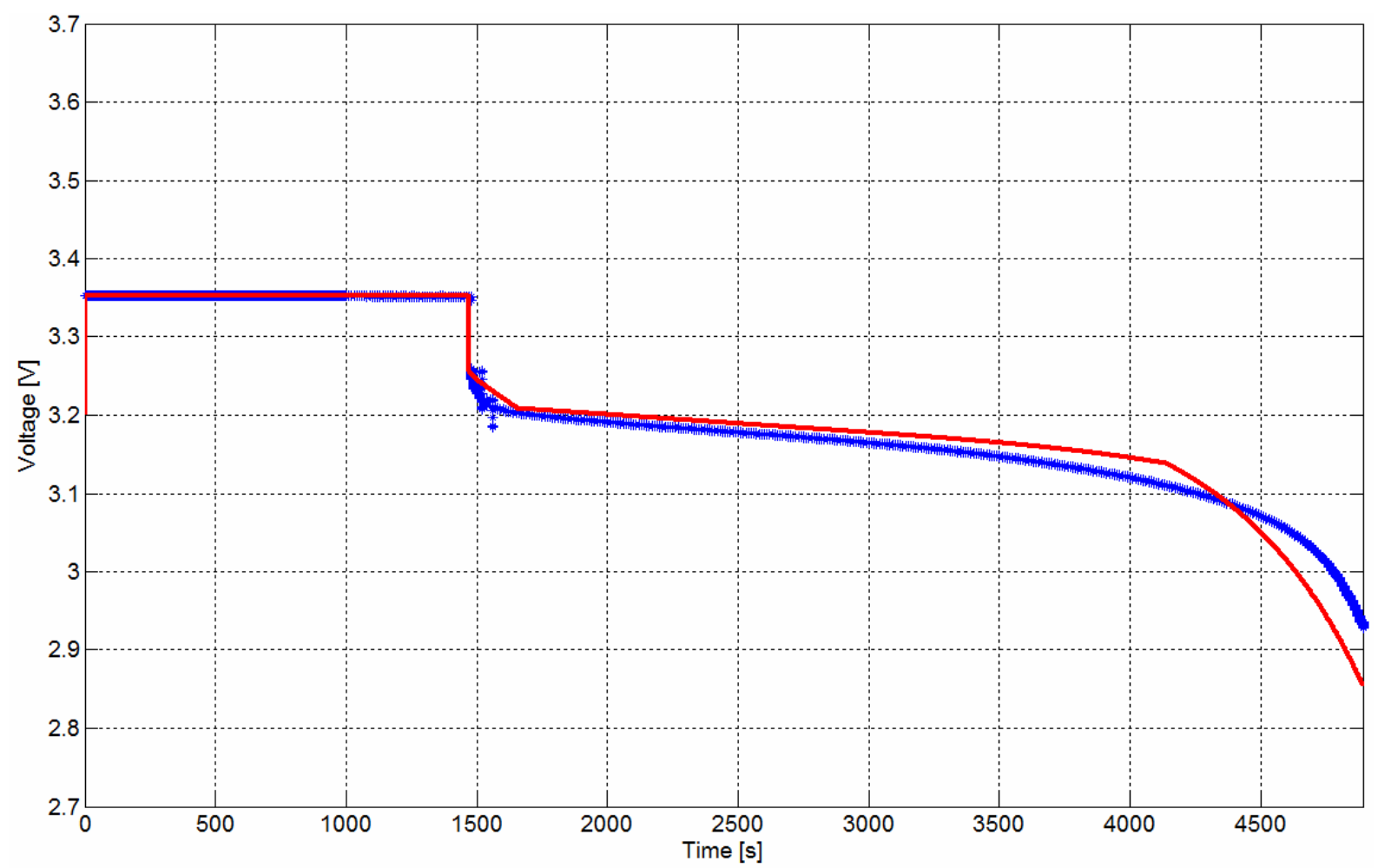

Figure 32. Zoomed in image of the voltage profile with GBSLFMP 60 AH for 1 C discharging [Blue: experimental, red: simulated]. 
value of the difference between the experimental and simulated values referred to the experimental values.

The difference occurring in the exponential region indicates that cell resistances are lower than the extracted values at that region. This would imply that this cell is healthier than other cells in the bank. It can work for extra time or extra Ahs compared with the cell that gives an alarm. During testing, temperature varies from $26^{\circ} \mathrm{C}$ to $30^{\circ} \mathrm{C}$ indicating that this temperature difference has negligible effect on the battery performance.

For more comparison, Figure 33 shows a zoomed in image of the simulated and experimental results of a 0.5 $\mathrm{C}$ continuous discharging current. The maximum operating time error for $0.5 \mathrm{C}$ occurs at the beginning of the exponential zone. Also, the maximum operating time error for $0.3 \mathrm{C}$ occurs at the beginning of the exponential zone as shown in Figure 34. For 1 C, $0.5 \mathrm{C}$ and $0.3 \mathrm{C}$ discharging currents, the error during the linear region is small. However, when the battery is discharged at $2 \mathrm{C}$ as in Figure 35, there is a long period operating time error of $45 \mathrm{mV}$ during the linear region. This error is because 2 $\mathrm{C}$ discharging current is far from the dynamic current at which parameters equations are extracted. Also, there was an alarm occurred many times that makes the discharging to be stopped. The interruptions during the discharging with $2 \mathrm{C}$ indicate that there is at least one cell inside the battery bank gave an alarm. This implies that the small error tolerances between the individual cells become large at higher currents.

Regarding the authors' applications, there is a $30 \mathrm{KW}$ vehicle under construction in KERI laboratory. The battery bank used in this vehicle is not used to receive re- generative energy during vehicle operation. Instead, a supercapacitor module will be used to recover such energy. Therefore, this paper focuses on the discharging mode to determine the area or SOC value at which the battery is working. During charging, the GBSLFMP 60 Ah battery bank was charged with constant current in a separate utility. The BMS gives an alarm if any cell terminal voltage increases $3.6 \mathrm{~V}$. Figure 36 shows the terminal voltage of the battery bank during charging with 1 $\mathrm{C}$ and discharging with $1 \mathrm{C}$ and $0.5 \mathrm{C}$. Unfortunately, during charging, the battery open circuit voltage does not follow Equation (5). The effect of current appears strongly at the battery terminal voltage. There is a long non-linear zone at the beginning. Also, the overcharge region is non-linear. Even at the linear region, the measured terminal voltage is higher than the calculated. Therefore, two-dimensional look-up table with interpolation can be implemented in ANSOFT SIMPLORER to represent the terminal voltage charging profile with SOC or time and Equation (4) can be used to determine the battery open circuit voltage.

\section{Conclusion}

This paper proposes an accurate modeling of lithium-iron-phosphate battery (LFP) battery. The model includes six parameters measured by an experimental manner as a function of SOC. The experimental results are carried out with two different batteries from the same production company. The battery parameters are fixed as SOC varies from $40 \%$ to $100 \%$. The battery current has slight effect on the battery parameters. The effect of

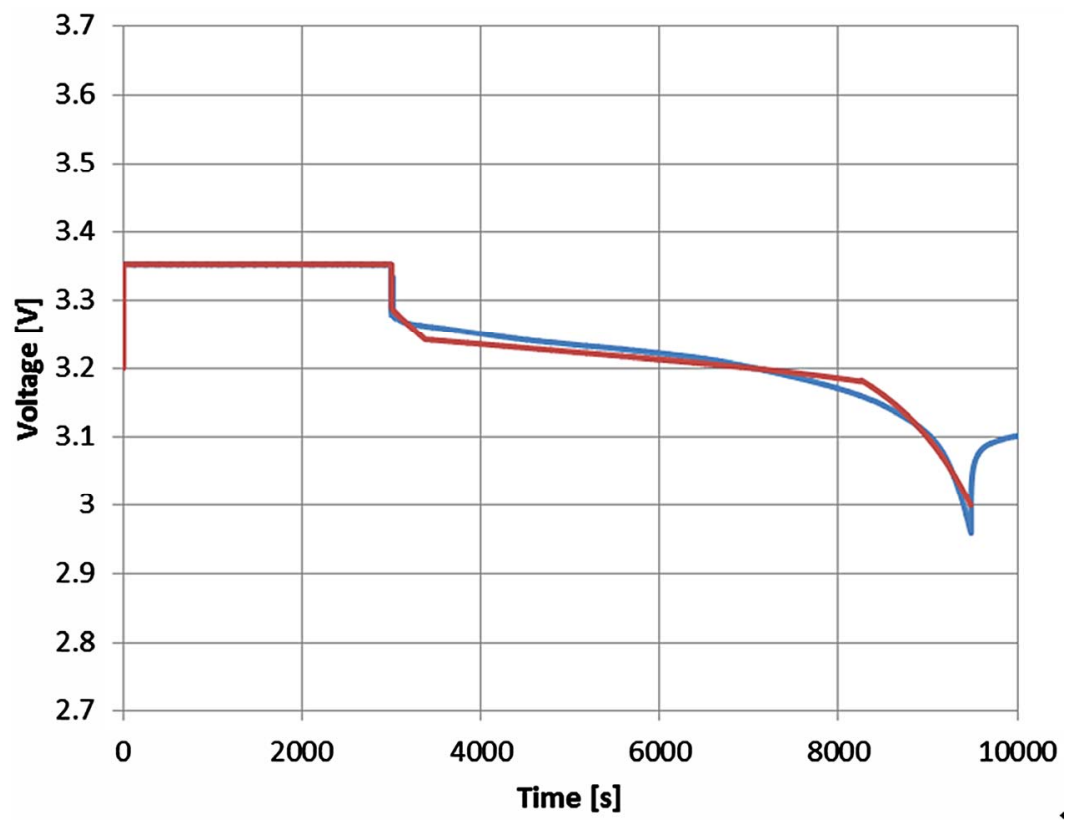

Figure 33. Voltage profile with GBSLFMP 60 AH for 0.5 C discharging. 


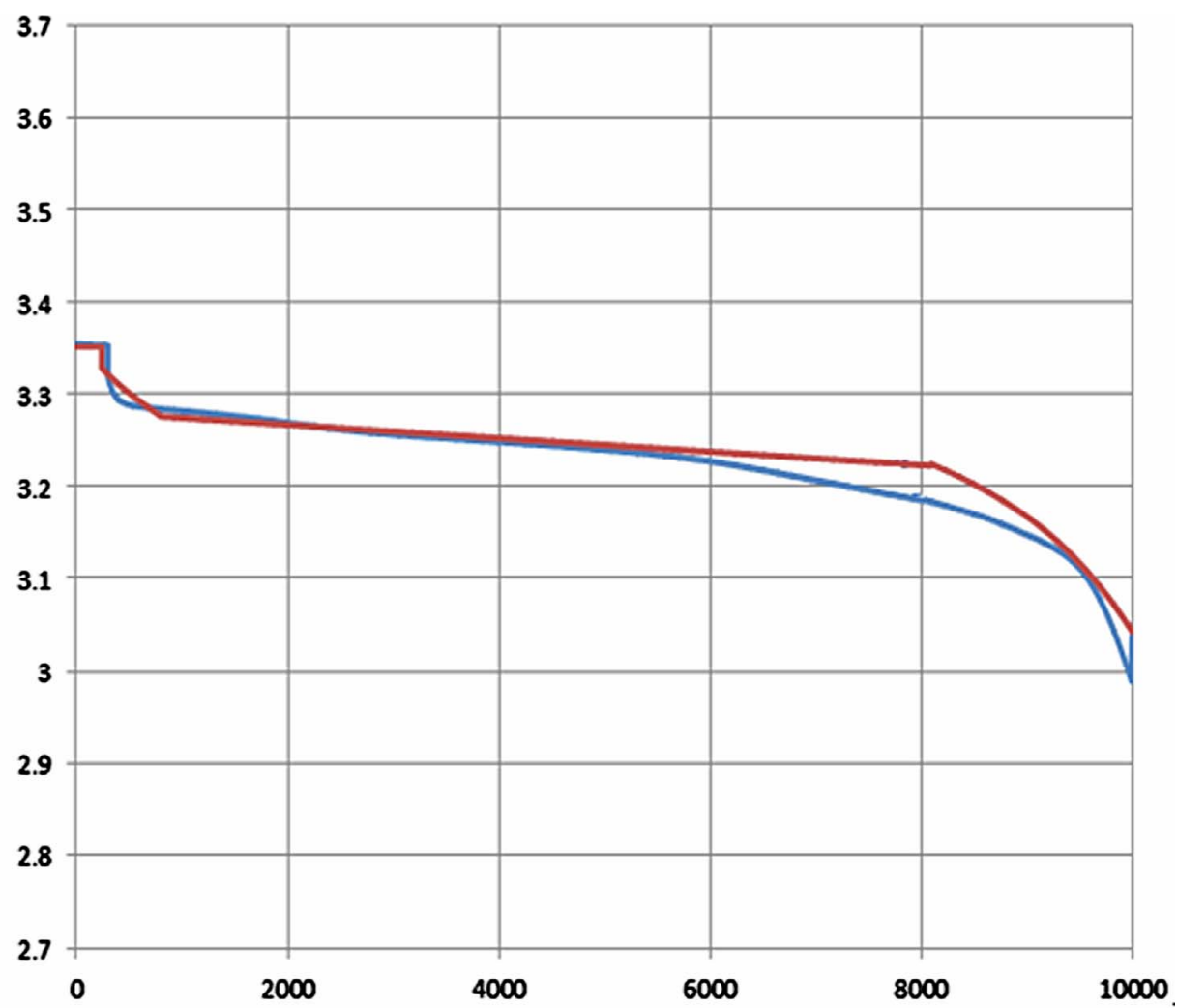

Figure 34. Voltage profile with GBSLFMP 60 AH for 0.3 C discharging [Blue: experimental, red: simulated].

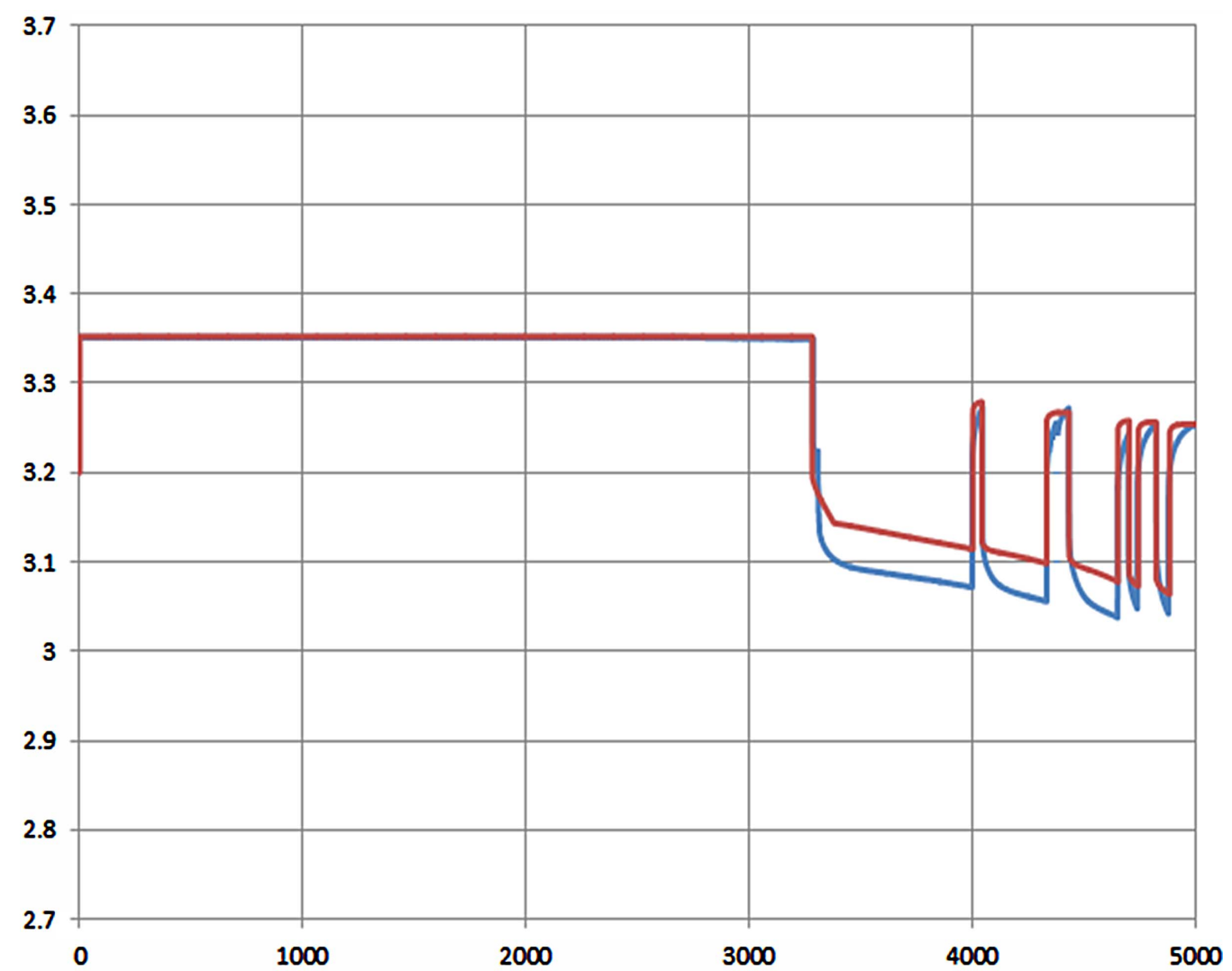

Figure 35. Voltage profile with GBSLFMP 60 AH for 2 C discharging [Blue: experimental, red: simulated]. 


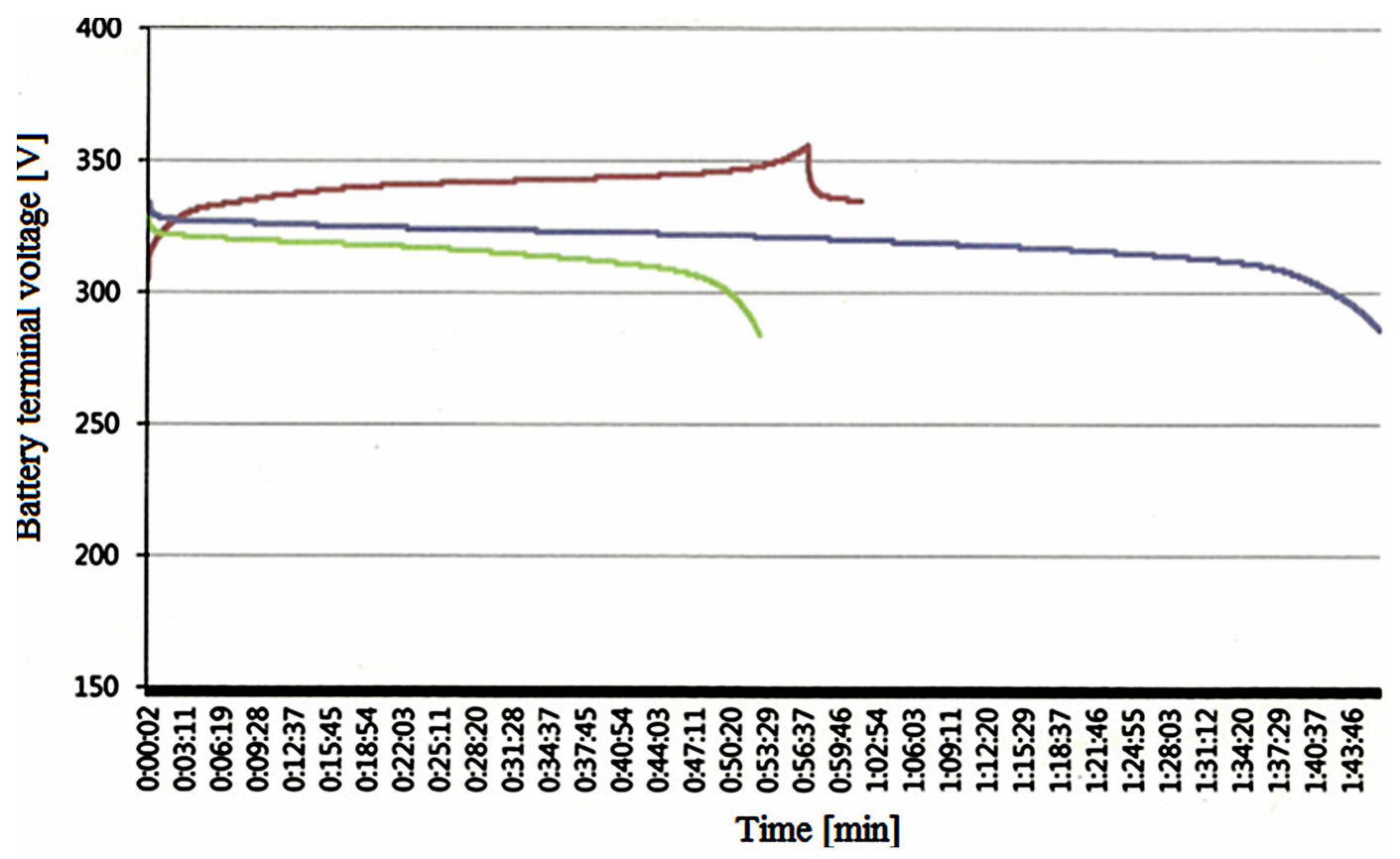

Figure 36. Measured terminal voltage profile with GBSLFMP 60 Ah bank [Brown: $1 \mathrm{C}$ charging, green: $1 \mathrm{C}$ discharging, blue: $0.5 \mathrm{C}$ discharging].

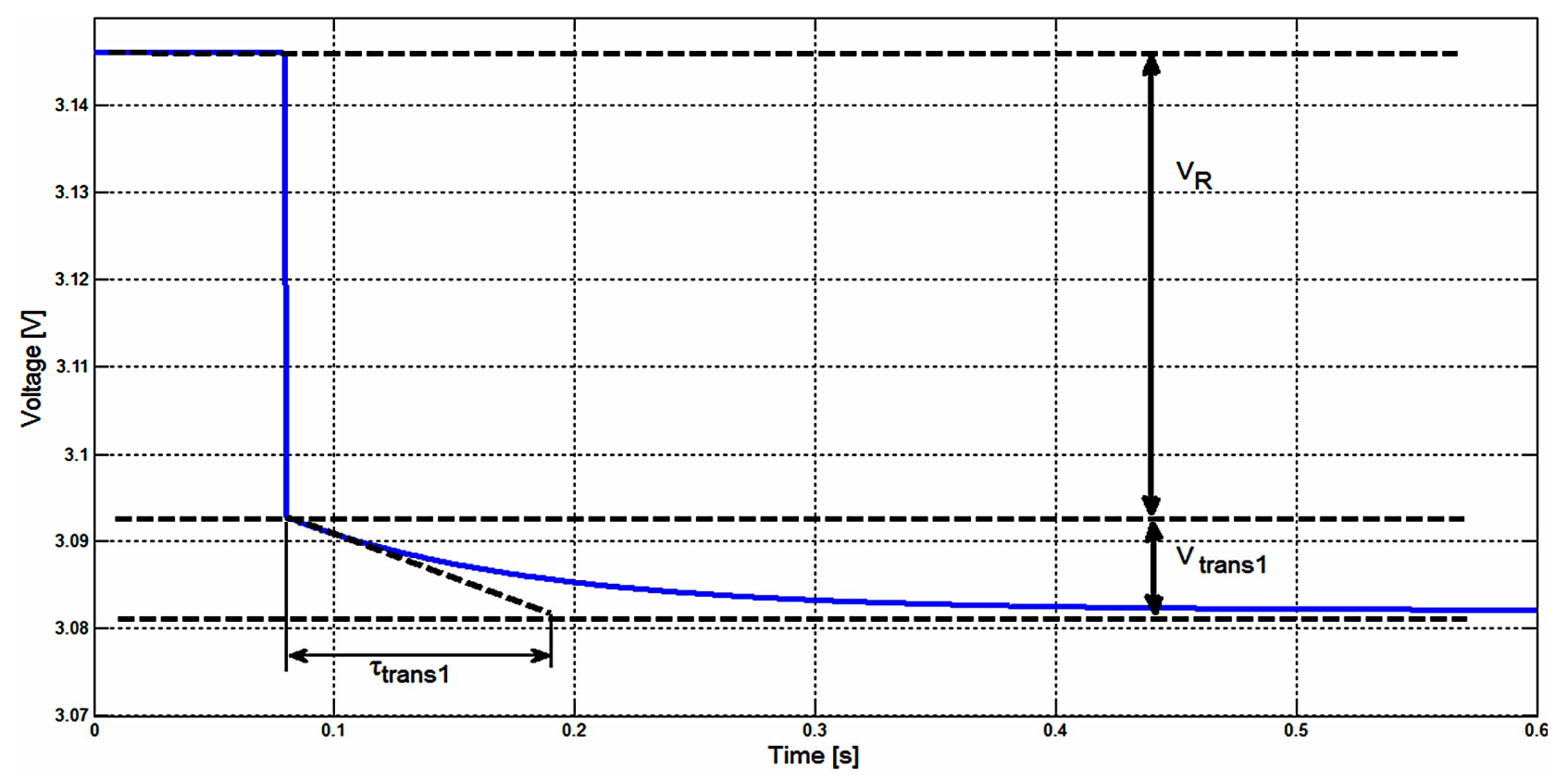

Figure 37. Analytical approximation of battery terminal voltage response due to a current pulse.

Table 7. Voltage error comparison results.

\begin{tabular}{ccc}
\hline Current & $\begin{array}{c}\text { Maximum error } \\
\text { voltage }(\mathrm{mV})\end{array}$ & Operating time error (\%) \\
\hline $2 \mathrm{C}$ & 45 & $1.48 \%$ \\
$1 \mathrm{C}$ & 50 & $1.7 \%$ \\
$0.5 \mathrm{C}$ & 10 & $0.3 \%$ \\
$0.3 \mathrm{C}$ & 30 & $0.9 \%$ \\
\hline
\end{tabular}

stacking is discussed in this paper. The battery voltage has three regions: exponential, linear and non-linear. The close agreement between the simulated and measured data indicates that the model can predict the battery performance to within $1.7 \%$ operating time error. For given battery terminal voltage and discharge current, especially during the linear region as the accuracy is very high, battery open circuit voltage can be estimated. Therefore, the model can be used to predict battery SOC. The model 
can be easily repeated and modified for different battery technologies and can be extended for wide dynamic ranges of different currents. In all, the model offers circuit and system engineers the possibility to improve the efficiency and size the LFP battery for automotive applications by predicting both the battery performance and I-V characteristics with co-simulation in ANSOFT SIMPLORER.

\section{REFERENCES}

[1] F. P. Tredeau and Z. M. salameh, "Evaluation of Lithium Iron Phosphate Vehicles for Electric Vehicle Application," IEEE Vehicle Power and Propulsion Conference, Dearborn, 7-10 September 2009, pp. 1266-1270.

[2] E. J. William, et al., "A Comparative Study of Lithium Poly-Carbon Monoflouride ( $\mathrm{Li} / \mathrm{CFx}$ ) and Lithium Iron Phosphate (LiFePO4) Battery Chemistries for State of Charge Indicator Design," IEEE International Symposium on Industrial Electronics, Seoul, 5-8 July 2009, pp. 20062009.

[3] C. H. Cai, D. Du, J. T. Ge, Z. Y. Liu and H. Zhang, "Battery-Charging Model to Study Transient Dynamics of Battery at High Frequency," IEEE Region 10 Conference on Computers, Communications, Control and Power Engineering, 28-31 October 2002, pp. 1843-1846.

[4] J. M. Miller, "Energy Storage System Technology Challenges Facing Strong Hybrid, Plug-In and Battery Electric Vehicles," IEEE Vehicle Power and Propulsion Conference, Dearborn, 7-10 September 2009, pp. 4-10.

[5] J. Larminie and J. Lowry, "Electric Vehicle Technology Explained," John Wiley \& Sons, Ltd., Chichester, 2003.

[6] H.-S. Kim, "Secondary Battery and Material," Korea Electrotechnology Research Institute (KERI) Lectures, June 2010, p. 17.

[7] P. Thounthong, V. Chunkag, P. Sethakul, B. Davat and M. Hinaje, "Comparative Study of Fuel-Cell Vehicle Hybridization with Battery or Supercapacitor Storage Device," IEEE Transactions on Vehicular Technology, Vol.
58 , No. 8,2009 , pp. $3892-3904$. doi:10.1109/TVT.2009.2028571

[8] C. S. Edrington, O. Vodyakho and B. A. Hacker, "Development of a Unified Research Platform for Plug-In Hybrid Electrical Vehicle Integration Analysis Utilizing the Power Hardware-in-the-Loop Concept," Journal of Power Electronics (JPE), Vol. 11, No. 4, 2011, pp. 471-478. doi:10.6113/JPE.2011.11.4.471

[9] J. Bauman and M. Kazerani, "A Comparative Study of Fuel-Cell-Battery, Fuel-Cell-Ultracapacitor and Fuel-CellBattery-Ultracapacitor Vehicles," IEEE Transactions on Vehicular Technology, Vol. 57, No. 2, 2008, pp. 760-769. doi:10.1109/TVT.2007.906379

[10] M. Ziyad, M. A. Salameh, W. A. Casacca and Lynch, "A Mathematical Model for Lead-Acid Batteries," IEEE Transactions on Energy Conversion, Vol. 7, No. 1, 1992, pp. 93-98.

[11] Y. Kim and H. Ha, "Design of Interface Circuits with Electrical Battery Models," IEEE Transactions on Industrial Electronics, Vol. 44, No. 1, 1997, pp. 81-86.

[12] K. S. Champlin and K. Bertness, "A Fundamentally New Approach to Battery Performance Analysis Using $\mathrm{DFRA}^{\mathrm{TM}} / \mathrm{DFIS}{ }^{\mathrm{TM}}$ Technology," 22nd International Telecommunications Energy Conference, Phoenix, 10-14 September 2000, pp. 1-6.

[13] M. Chen and G. A. Ricon-Mora, "Accurate Electrical Battery Model Capable of Predicting Runtime and I-V Performance," IEEE Transactions on Energy Conversion, Vol. 21, No. 2, 2006, pp. 504-511.

[14] B. Schweighofer, K. M. Raab and G. Brasseur, "Modeling of High Power Automotive Batteries by the Use of an Automated Test System," IEEE Transactions on Instrumentation and Measurement, Vol. 52, No. 4, 2003, pp. 1087-1091. doi:10.1109/TIM.2003.814827

[15] A. Szumanowski and Y. Chang, "Battery Management System Based on Battery Nonlinear Dynamics Modeling," IEEE Transactions on Vehicular Technology, Vol. 57, No. 3, 2008, pp. 1425-1432. doi:10.1109/TVT.2007.912176

\section{Appendix A}

The determination of the equivalent circuit model parameters for constant SOC and temperature can be obtained by investigating the battery terminal voltage profile of a current pulse as shown in Figure 37. The internal resistance and the short term time constant can be defined by investigating the first $0.5 \mathrm{~s}$ of the terminal voltage profile. The solution of the resulting waveform can be approximated to Equation (11). The designation $t$ and $v(t)$ corresponds to the time and terminal voltage respectively. Hence, the battery internal resistance $\left(R_{b s}\right)$, short term constant resistance $\left(R_{\text {trans } 1}\right)$ and short term constant capacitance $\left(C_{\text {trans } 1}\right)$ can be obtained according to Equations (12)-(14). Investigating the remaining part of the waveform, the long term time constant parameters can be obtained in a similar manner.

$$
\begin{gathered}
v(t)=E_{o c}-\left[V_{R}+V_{\text {trans } 1}\left(1-\mathrm{e}^{-\left(t / \tau_{\text {trans } 1}\right)}\right)\right] . \\
R_{b s}=V_{R} / I . \\
R_{\text {trans } 1}=V_{\text {trans } 1} / I . \\
C_{\text {trans } 1}=\tau_{\text {trans } 1} / R_{\text {trans } 1} .
\end{gathered}
$$

